\title{
Axon microdissection and transcriptome profiling reveals the in vivo RNA content of fully differentiated myelinated motor axons
}

\author{
JOAQUINA FARIAS, ${ }^{1,2,5}$ CHRISTINE E. HOLT, ${ }^{3}$ JOSÉ R. SOTELO, $^{2}$ and JOSÉ R. SOTELO-SILVEIRA ${ }^{1,4}$ \\ ${ }^{1}$ Departamento de Genómica, Instituto de Investigaciones Biológicas Clemente Estable, Montevideo, 11600, Uruguay \\ ${ }^{2}$ Departamento de Proteínas y Ácidos Nucléicos, Instituto de Investigaciones Biológicas Clemente Estable, Montevideo, 11600, Uruguay \\ ${ }^{3}$ Department of Physiology, Development and Neuroscience, University of Cambridge, Cambridge, CB2 3DY, United Kingdom \\ ${ }^{4}$ Departamento de Biología Celular y Molecular, Facultad de Ciencias, Universidad de la República, Montevideo, 11400, Uruguay
}

\begin{abstract}
Axonal protein synthesis has been shown to play a role in developmental and regenerative growth, as well as in the maintenance of the axoplasm in a steady state. Recent studies have begun to identify the mRNAs localized in axons, which could be translated locally under different conditions. Despite that by now hundreds or thousands of mRNAs have been shown to be localized into the axonal compartment of cultured neurons in vitro, knowledge of which mRNAs are localized in mature myelinated axons is quite limited. With the purpose of characterizing the transcriptome of mature myelinated motor axons of peripheral nervous systems, we modified the axon microdissection method devised by Koenig, enabling the isolation of the axoplasm RNA to perform RNA-seq analysis. The transcriptome analysis indicates that the number of RNAs detected in mature axons is lower in comparison with in vitro data, depleted of glial markers, and enriched in neuronal markers. The mature myelinated axons are enriched for mRNAs related to cytoskeleton, translation, and oxidative phosphorylation. Moreover, it was possible to define core genes present in axons when comparing our data with transcriptomic data of axons grown in different conditions. This work provides evidence that axon microdissection is a valuable method to obtain genome-wide data from mature and myelinated axons of the peripheral nervous system, and could be especially useful for the study of axonal involvement in neurodegenerative pathologies of motor neurons such as amyotrophic lateral sclerosis (ALS) and spinal muscular atrophies (SMA).
\end{abstract}

Keywords: axonal mRNAs; mRNA localization; motor neuron; local translation; axon

\section{INTRODUCTION}

Neurons are highly specialized cells which present an exceptional morphology, composed of somatodendritic and axonal compartments. A key issue in neurobiology has been to understand the cellular mechanisms that maintain the dendritic and axonal structures, which are essential for neuronal function. The axonal transport is the main mechanism that sustains the proteostasis of the axonal compartment. This process consists in the transport of proteins and other materials synthesized in the soma to the axon using molecular motors and the cytoskeleton (for reviews, see Roy 2014; Black 2016). The speed of this transport (ranging from $0.1-20$ to $200-400 \mathrm{~mm} / \mathrm{d}$ ) does not

\footnotetext{
${ }^{5}$ Present address: PDU "Espacio de Biología Vegetal del Noreste," Centro Universitario de Tacuarembó, Universidad de la República, Tacuarembó, 45000, Uruguay

Corresponding author: jsotelosilveira@iibce.edu.uy

Article is online at http://www.rnajournal.org/cgi/doi/10.1261/rna. 073700.119.
}

allow a rapid response to external or internal cues. However, complementary mechanisms have been described that can contribute in this regard. These include transference of macromolecules from glia-to-axon (for reviews, see Sotelo et al. 2014; López-Leal et al. 2016) and local protein synthesis in the axon (for reviews, see Glock et al. 2017; Cioni et al. 2018). The relative contribution of each mechanism is not yet known and has been described as variable depending on the developmental stage or under injury conditions (for reviews, see Cornejo et al. 2017; Glock et al. 2017; Cioni et al. 2018).

RNA localization and local protein synthesis are conserved mechanisms that can confer precise spatial and temporal control of protein levels. In the case of mammals,

(C) 2020 Farias et al. This article is distributed exclusively by the RNA Society for the first 12 months after the full-issue publication date (see http://rnajournal.cshlp.org/site/misc/terms.xhtml). After 12 months, it is available under a Creative Commons License (Attribution-NonCommercial 4.0 International), as described at http:// creativecommons.org/licenses/by-nc/4.0/. 
the first lines of evidence of mRNA localization in axons were obtained using in situ hybridization for candidate genes (Jirikowski et al. 1990; Mohr and Richter 1992; Mohr et al. 1991; Skutella et al. 1994). The possibility to separate axons from the cell body and other types of cells by using compartmentalization cultures allowed for the study of the axonal transcriptome from a genome-wide perspective. Although the localization of mRNA does not imply that it is locally translated per se, it does provide evidence of the potentiality of the axon to synthesize proteins and rapidly and autonomously respond to its environment. With this aim, almost 20 data sets have been produced, where axonal transcriptome of different species, diverse neuronal types, and physiological conditions, were studied in vitro (for review, see Farias et al. 2019). These data indicate a high diversity of mRNAs localized in immature axons, with variations depending on the developmental stage and conditions.

Many efforts have been directed at understanding the role of RNA localization and local translation in axonal physiology (for reviews, see Glock et al. 2017; Cioni et al. 2018; Farias et al. 2019). However, the importance of these mechanisms for mature myelinated axons in their normal microenvironment is not yet known. This is mainly due to the difficulty of obtaining pure axonal cytoplasm from in vivo samples, and the small amount of RNA obtained from them. The mechanical extrusion of giant axon of invertebrates (Squid, Aplysia) has been used as a method to obtain pure axoplasm in large amounts for diverse posterior analyses, including cDNA libraries (Capano et al. 1987) and RNA-seq (Mathur et al. 2018). In the case of mammals, there are two methodological approaches available to obtain axoplasm from in vivo nerves: extrusion (Rishal et al. 2010) and microdissection (for review, see Koenig 2009) of axoplasm. The extrusion method has been used to characterize the total proteome of sciatic nerve axoplasm, identifying 540 proteins (Rishal et al. 2010). In addition, it was also used to examine the link between axonal injury signaling and the resultant cell body response using phosphoproteomics in rat sciatic nerve (Michaelevski et al. 2010). On the other hand, our group has widely used the microdissection technique to conduct in situ analysis of components of the axoplasm derived from medullary roots of rats and rabbits (Koenig et al. 2000; Sotelo-Silveira et al. 2004, 2008; Kun et al. 2007; Calliari et al. 2014).

In this work, we modified the microdissection protocol to achieve the goal of characterizing the transcriptome of mature and myelinated motor axons of the peripheral nervous system (PNS). With this method we obtained pure axonal cytoplasm from rat ventral roots and performed RNA-seq of transcripts localized in this subcellular domain. Quality controls performed in the axoplasm sample indicate that the preparation is enriched in neuronal markers and depleted from glial markers. This is an approach that reveals that mature axons in vivo have a lower number of RNA species in comparison with those growing in culture (in vitro axons). The gene ontology (GO) categories enriched in the axoplasm transcriptome are mainly related to translation, mitochondria, and cytoskeleton. Moreover, it was possible to define core transcripts present in axons when comparing our data with transcriptomic data of axons grown in different conditions. This work provides evidence that axon microdissection is a valuable method to obtain data from mature and myelinated axons of the PNS at genome-wide levels, and could be especially useful for the study of axonal involvement in neurodegenerative pathologies of motor neurons such as amyotrophic lateral sclerosis (ALS) and spinal muscular atrophies (SMA).

\section{RESULTS}

\section{Isolation of pure axoplasm from mature myelinated motor axons}

In order to characterize the transcriptome of mature myelinated axons, a method of obtaining axonal cytoplasm with a purity level that allows for molecular analysis is necessary. To achieve this objective, we optimized the axon microdissection technique, a method used to isolate axoplasm from both Mauthner cells and mammalian medular roots (Koenig 1979, 1986, 1991; Koenig and Martin 1996; Koenig et al. 2000; Sotelo-Silveira et al. 2004, 2008; Calliari et al. 2014), originally developed by Koenig (1979). In this work, we isolated motor axons from lumbar ventral roots of adult rats (Fig. 1A). After a denaturing step using zinc (Fig. 1B,i), which increases the efficiency of axoplasm isolation, we proceeded to the "pulling out" of multiple axoplasmic whole-mounts in aspartate solution (Fig. 1B,ii). To minimize the potential remnants of myelin on the surface of the axoplasms, these were condensed into a compact bundle and washed several times by gently drawing the axons in and out of the solution except for one end, repeating this procedure several times (Fig. 1B,iii). This dislodged-by the force of surface tension-the scanty debris of myelin still attached to the axons. Then, the condensed bundle was attached at both ends to a coated coverslip (Fig. 1B,iv) to remove the tip of the bundle using a scalpel (Fig. 1B,v). Once the bundle is attached, further washes were made to decrease the likelihood of nonaxonal contamination. (Fig. 1B,vi). Finally, the axoplasms were detached from the coverslip and stored at $-80^{\circ} \mathrm{C}$ in an Eppendorf until the RNA extractions were performed (Fig. 1B,vii).

Two different quality control steps were performed to evaluate, qualitatively and quantitatively, the presence of myelin in the preparation. The first was to detect myelin remnants using fluorescent microscopy or scanning electron microscopy (Fig. 1C-E). The second was to assess the presence of mRNA markers of myelin and axon 


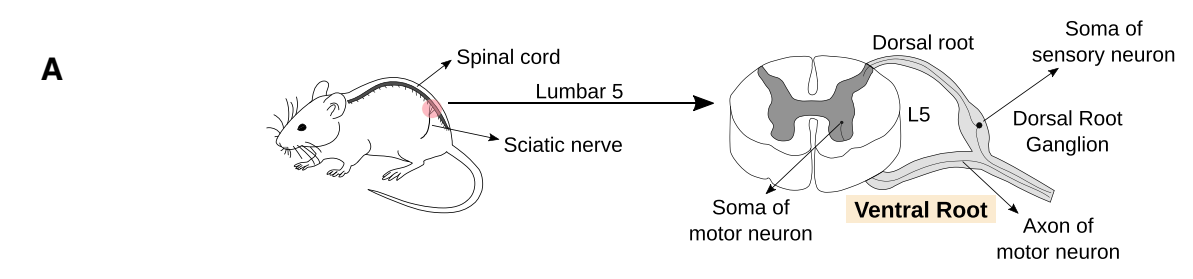

B

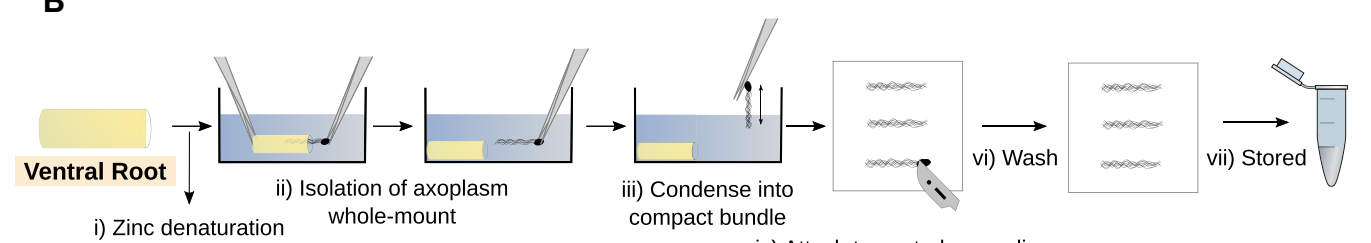

iv) Attach to coated coverslip

v) Removal of tissue
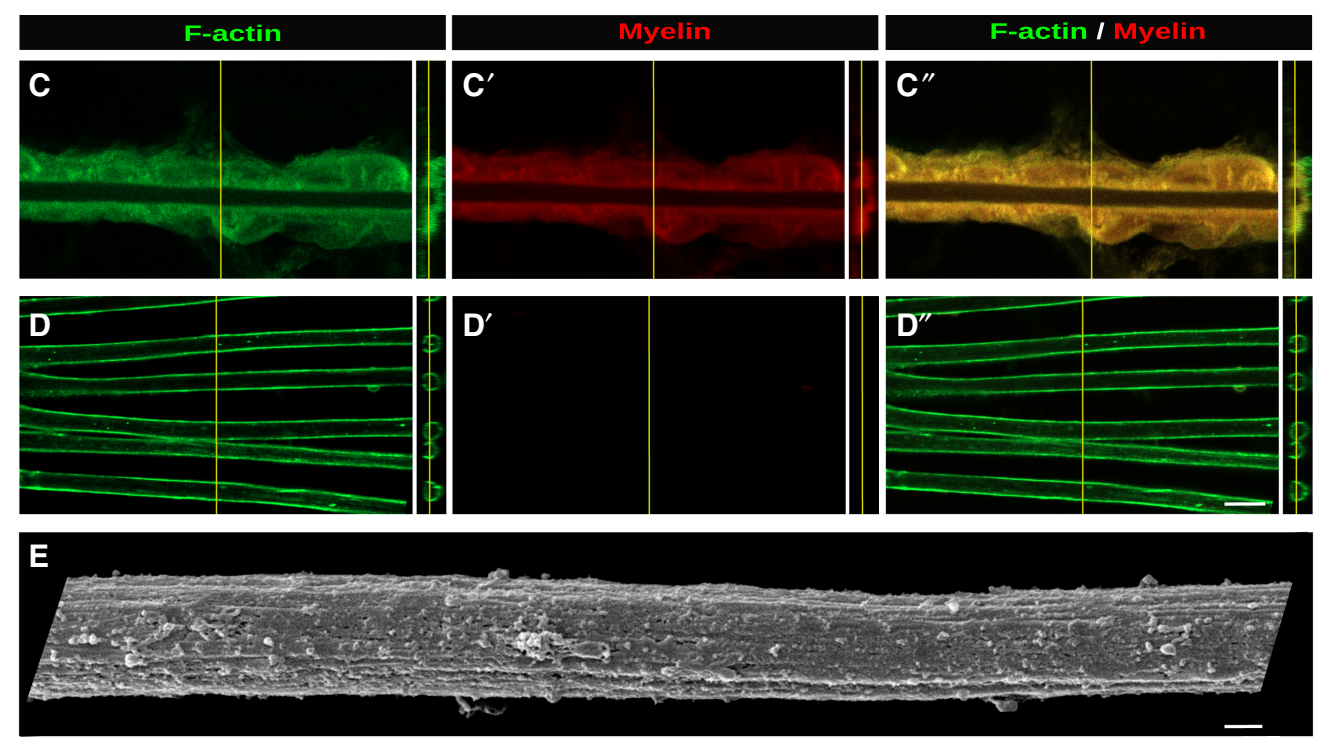

FIGURE 1. Axoplasm whole-mounts, obtained by microdissection method, are depleted of myelin. (A) Schematic diagram of rat spinal cord with dorsal and ventral lumbar spinal roots assembling into the sciatic nerve. In this work, the L5 lumbar ventral roots containing axons from motor neurons were dissected out for isolation of RNA. (B) Experimental procedure of the microdissection technique to obtain axoplasm whole-mounts from spinal roots. $C-C^{\prime \prime}$ and $D-D^{\prime \prime}$ : Single focal plane and orthogonal projection of $z$-stack of ventral root axons before $\left(C-C^{\prime \prime}\right)$ and after $\left(D-D^{\prime \prime}\right)$ the microdissection procedure. Note that the lipid-rich structures, such as myelin, are stained with the lipophilic fluorescent dye Nile red (red) in $C^{\prime}$, and the F-actin cortex can be observed in $D$, stained with fluorescent phalloidin (green). (E) A representative image from scanning electron microscopy of a microdissected axon. Scale bars: (D) $10 \mu \mathrm{m}$; (E) $2 \mu \mathrm{m}$

compartments by quantitative real time RT-PCR (Fig. 2). In the first case, we visualized axons stained with phalloidin and the fluorescent lipophilic dye Nile Red before (Fig. 1C-C'"') and after (Fig. 1D-D'"') the isolation steps to reveal possible remnants of myelin. As can be seen when comparing Figure $1 \mathrm{C}^{\prime}$ and $\mathrm{D}^{\prime}$, the isolated axons did not show detectable Nile Red staining of myelin in the axoplasm surface, while the actin rich cortex of the axoplasm is preserved (Fig. 1C,D). The performance of the method was tested at a higher resolution using scanning electron microscopy, where the axoplasm surface free of myelin debris could be observed (Fig. 1E).

To analyze the purity of the axoplasm sample with higher sensitivity than optical methods, we implemented a mo- lecular quality control, performing RT-qPCR of mRNA markers of myelin (Mbp, Pmp22, and Mag) and axon (Nefl, Nefm, and Nefh) compartments (Fig. 2). The glial markers were chosen according to their subcellular localization in glial cells (Fig. 2A). In sciatic nerve, it has been described that Mag (Griffiths et al. 1989) and Pmp22 (Snipes et al. 1992) mRNAs have a perinuclear distribution, while Mbp mRNA was detected diffusely in the Schwann cell internode and predominantly in the paranodal cytoplasm (Griffiths et al. 1989). Furthermore, in oligodendrocytes it was described that Mbp mRNA could be transported to the axon-glial contact site and locally translated (White et al. 2008). Comparison of relative abundance levels in axons versus whole ventral root tissues for all these markers 


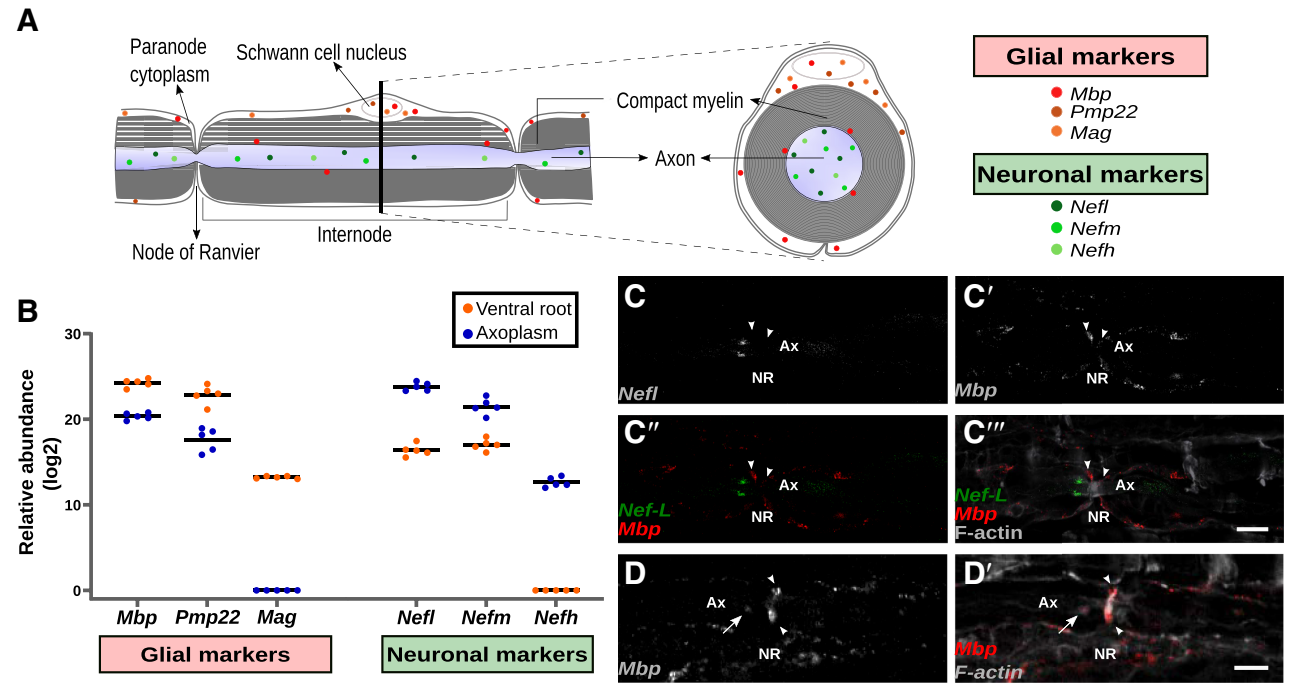

FIGURE 2. Axoplasm samples are reduced in glial mRNAs and enriched in neuronal mRNAs. (A) Schematic diagram showing longitudinal and transverse sections of a myelinated peripheral axon where the axon, node of Ranvier, the paranodal cytoplasm, and the internode are shown. The localization of glial and neuronal mRNA markers used to perform the quality control of axoplasm samples is shown by color coded solid dots. (B) Molecular quality control of purity of axoplasm samples by RT-qPCR. Relative quantification of glial (Mbp, Mag, and Pmp22) and neuronal markers (Nefl, Nefm, and Nefh) in different axoplasmic and ventral root samples isolated from five individual animals. (C-C $\left.C^{\prime \prime \prime}\right)$ Single molecule FISH (smFISH) of Nefl (green) and Mbp (red) mRNAs in ventral root crysections confirming the localization of an axonal marker (Nefl) and a glial marker (Mbp). Phalloidin F-actin staining (white) delineated the shape boundaries of Schwann cell and axon. Note that Nefl is localized into axons $(A x)$, while the Mbp mRNA is preferentially located close to the axon at paranode cytoplasm of Schwann cell (arrow heads). (D-D') smFISH of Mbp mRNAs in ventral root crysections, showing its location preferentially close to the axon at paranode cytoplasm of Schwann cell (arrowheads) and, in some cases, at the axon-glia contact site (arrow). (Ax) Axon, (NR) node of Ranvier. Scale bar, $10 \mu \mathrm{m}$.

yielded the conclusion that glial markers decrease their abundance in axoplasm samples between 15-fold for Mbp mRNA, and more than 35-fold for Pmp22 and Mag mRNAs (Fig. 2B, relative abundance expressed in $\log _{2}$ : Mbp: $20.345 \pm 0.402$ and 24.246 $\pm 0.484 ;$ Pmp22: 17.601 \pm 1.360 and $22.868 \pm 0.148$ and Mag: not detectable and $13.202 \pm 1.091$; in axoplasm and ventral root samples, respectively). Due to its subcellular distribution in the internal mesaxon, close to the axon-glial contact site, the Mbp mRNA indicated that only locations establishing intimate interactions with the axon remain at reduced levels after the isolation procedure used. In contrast, the neuronal markers increased their abundance in axoplasm samples in comparison with ventral root samples from 22- to more than 172-fold (Fig. 2B, relative abundance expressed in $\log _{2}:$ Nefl: $23.811 \pm 0.493$ and $16.380 \pm 0.699$; Nefm: $21.499 \pm 0.952$ and $17.012 \pm 0.670$ and Nefh: $12.642 \pm 0.583$ and not detected; in axoplasm and ventral root samples, respectively). In order to analyze the subcellular distribution of markers in our model, we performed single molecule FISH (smFISH) of Mbp and Nefl mRNAs in ventral roots cryosections (Fig. $\left.2 \mathrm{C}-\mathrm{C}^{\prime \prime \prime}\right)$. The Nefl mRNA was present exclusively in the axon cytoplasm, showing different fluorescence signal patterns, from discrete and pointed to more diffuse (Fig. 2C; Supplemental Fig. S1). The Mbp mRNA was localized at the internode and paranode cytoplasm of the Schwann cell (Fig. 2C'-C'" and $D-D^{\prime}$ ), as previously described (Griffiths et al. 1989). Additionally, it was also confirmed that Mbp mRNAs are located in axon-glial contact sites in peripheral nerves (Fig. 2D-D', arrow), as described in oligodendrocytes (White et al. 2008).

Thus, we can affirm that axoplasm samples have minimal glial components but mainly contain neuron specific mRNAs. It is important to note that five independent biological replicas were used to ascertain the variability of the method (Fig. 2B), yielding a very tight distribution among them (coefficient of variation [\%] $=2.62 \pm 1.18$ ). For the subsequent RNA-seq study, due to the low yield of total RNA contained within this axonal preparation (typically in the picogram range), five biological replicates were pooled and linear amplified for the generation of a single RNA sample representative of axoplasm, performing the same procedure with the ventral root samples to avoid bias.

\section{Mature myelinated axons have a unique transcriptional profile, with less complexity than in vitro grown axons}

To investigate the transcriptome of mature myelinated axons, we sequenced total RNA (linear amplified) from five pooled samples of both ventral roots and axoplasm. The number of detected genes was 11,333 in ventral roots and 1008 in axoplasm (Supplemental Table S1). In 
total, 10,396 genes expressed in ventral roots were undetectable in axons. On the other hand, 71 genes detected in axoplasm were undetectable in ventral roots (Fig. 3A). The number of detected genes in mature myelinated axons is much lower than those previously described for in vitro axons (for review, see Farias et al. 2019). In order to evaluate if the low number of detected genes is due to a library construction or sequencing artifact we performed saturation plots. The number of detected genes as a function of the sequencing depth indicates that saturation is reached for both ventral roots and axon samples, globally and in a protein coding category (Fig. 3B).

To demonstrate that the axonal transcriptome is not merely the product of a contamination of the most abundant transcripts present in the ventral roots, we conducted a series of analyses. Gene abundance as a function of gene position (ranking) in an axoplasm sample clearly shows that not all genes detected in axons are highly expressed in ventral roots (Fig. 3C). Furthermore, the 71 axonal genes not detected in ventral roots (see Fig. $3 \mathrm{~A}$ ) include RNAs from low to high abundance (Fig. $3 \mathrm{C}$ ), indicating the spec- ificity of the axoplasm isolation method. The correlation analysis for genes detected in both samples (937 genes) also showed that the axoplasm sample has a different pattern of gene abundance (Fig. 3D, $R^{2}=0.28$ ). In addition, analysis of the top 50 abundant genes in axoplasm and ventral roots indicated that 29 of these were in common, but nearly the same proportion was unique to the axon extract (Fig. 3E). The common genes mainly code mitochondrial proteins (encoded by the mitochondrial genome) as well as ncRNAs and pseudogenes. It is important to note that among the most abundant genes in the ventral root sample we found glial markers (such as Mbp, Mag, Pmp22, S100b, Mpz), which presented low abundances in the axoplasm sample as shown in the heatmap (Fig. 3E).

In summary, our analysis indicates that axon microdissection is a useful technique to obtain axoplasms from mature myelinated neurons derived from PNS for subsequent analysis at the molecular level. The number of RNAs detected in mature axons is lower in comparison with in vitro data, is depleted of glial markers, and is enriched in neuronal markers.
A

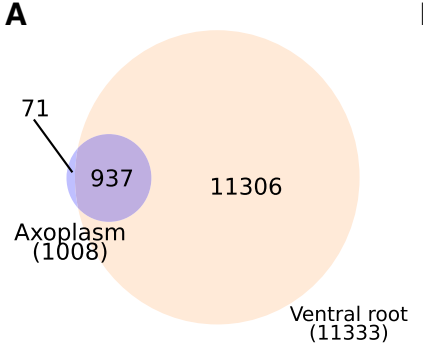

B

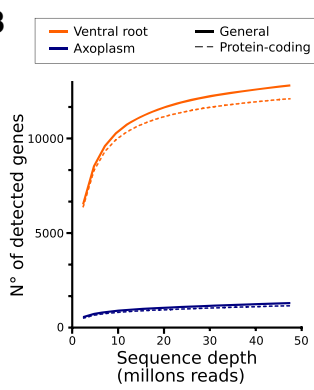

C

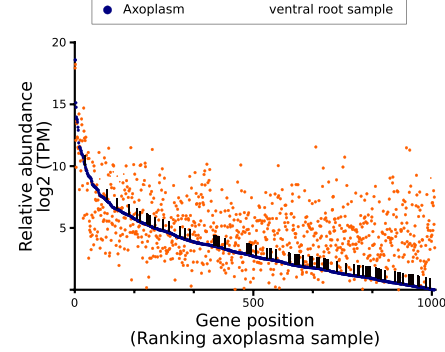

D

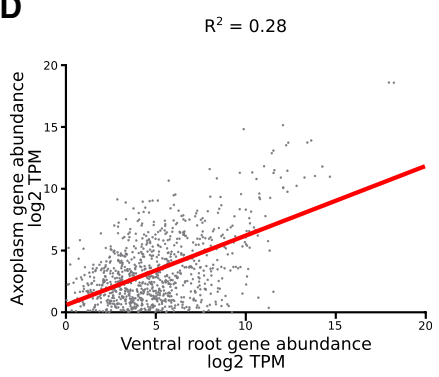

E

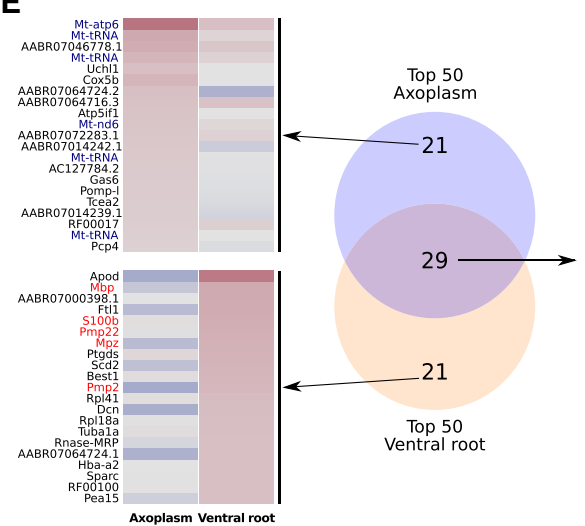

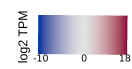

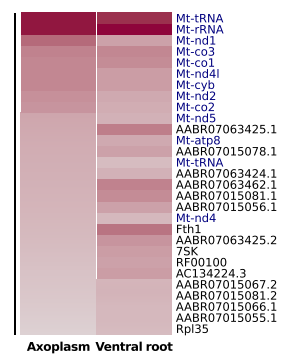

FIGURE 3. RNA-seq of microdissected motor axons. (A) Venn diagram showing number of detected genes on ventral root and axoplasm samples. Note that 937 genes are common to both while 71 are only detected in the axoplasm. (B) Saturation plot of ventral root and axoplasm RNAseq data. Solid lines indicate the global saturation plot and dashed lines indicate the saturation for protein-coding genes. (C) Relative abundance $\left(\log _{2}\right.$ TPM) of genes detected in axoplasm sample (blue dots) in function of their ranking in the sample. The abundance in ventral root sample is also shown (orange dots). The 71 genes detected in axoplasm sample and not in ventral root sample (shown as a black line) are not necessarily present at low abundance. (D) Correlation analysis of the 937 genes detected in both samples. The linear regression $r^{2}$ (goodness-of-fit) is 0.28 . (E) Of the top 50 highest abundant genes in ventral root and axoplasm samples, 29 overlapped. The heatmap of abundance values of the top highest abundant genes in both samples is also shown. RNAs encoded by the mitochondrial genome are labeled in blue and mRNAs coding myelin proteins are marked in red. 
A

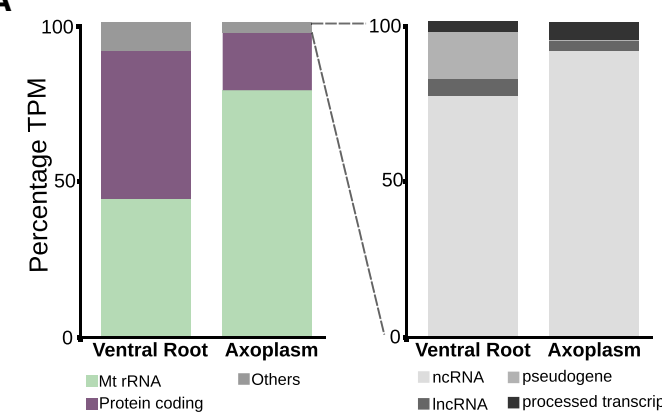

B
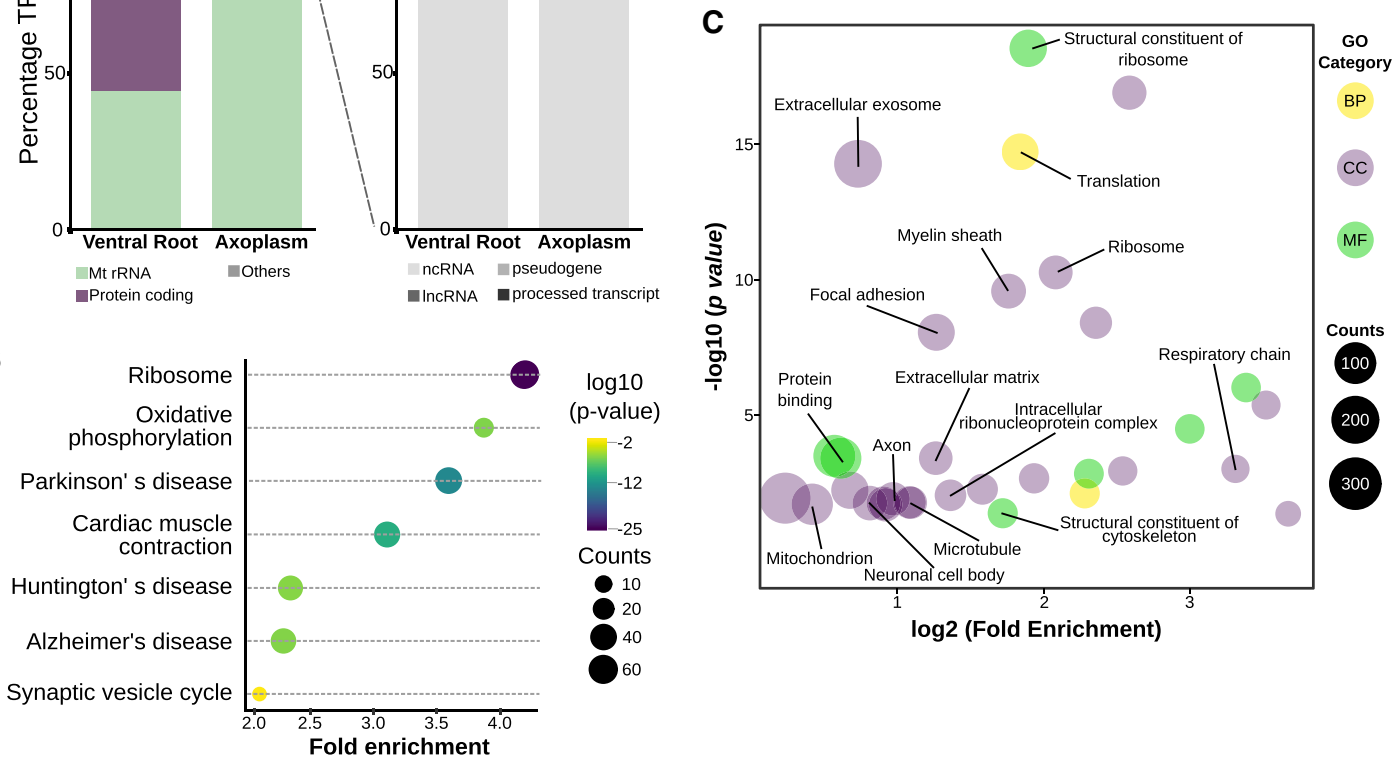

FIGURE 4. Characterization of mature motor axons transcriptome. (A) Quantification of different gene biotypes detectable in ventral root and axoplasm samples. Only detected transcripts were considered. Data are percentages as stacked bars, showing abundant categories such as mitochondrial RNAs and protein coding. (B) KEGG pathway analysis of axoplasm transcriptome. Bubble chart shows enrichment of detected genes in KEGG pathways. Y-axis label represents pathways, and $x$-axis represents fold enrichment factor (ratio between the amount of expressed genes enriched in the pathway and the amount of all genes in background gene set ventral root transcriptome). Size of the bubble represents amount of detected genes enriched in pathway and color represents the enrichment significance. (C) Enrichment of GO terms in the axoplasm transcriptome, with ventral root transcriptome as background. Y-axis represents Benjamini corrected $P$-value $\left(-\log _{10}\right)$, and $x$-axis represents fold enrichment factor $\left(\log _{2}\right)$. Size of the bubble represents amount of detected genes enriched in pathway and color represents the GO category. (BP) Biological process, (CC) cellular component, (MF) molecular function.

\section{Mature myelinated axons are particularly enriched in transcripts important for mitochondrial and protein synthesis functions}

To assess the transcriptome complexity of axoplasm samples we first evaluated the different biotypes of transcripts present in each sample. We found that the RNA composition of axoplasm was similar to that described for motor axons in culture (Briese et al. 2015), containing transcripts of multiple classes, including protein coding, Mt-rRNA, ncRNA (such miscRNA, snoRNA, and rRNA), IncRNA and pseudogenes (Fig. 4A; Supplemental Table S1). In addition, in the axoplasm sample, it was observed that the percentage of TPM of the mitochondrial rRNAs (Mt-rRNA) was almost twice that in whole tissue (78\% compared to $43 \%)$, similar to observations made in the comparison of the axon with the somatodendritic compartment in motoneurons in culture (Briese et al. 2015). Moreover, the mature motor axons possess the noncoding 7SL RNA, which form part of the eukaryotic signal recognition particle (SRP), previously described in in vitro motoneurons (Briese et al. 2015) and the SRP particle in axoplasmic whole-mounts (Koenig 2009). In the case of miRNAs, although their presence in the axons has already been described (for review, see Wang and Bao 2017), we only detected some putative miRNAs precursors since the library protocol was not specific for small RNAs.

In order to continue with the characterization of the mature myelinated axon transcriptome, we studied the functional enrichment of the localized RNAs. The functional annotation analysis was performed using the axoplasm transcripts as the target list and the ventral root transcripts as the background (Fig. 4B,C; Supplemental Table S2). The KEGG pathways enriched in the axoplasm sample were "Ribosome," "Oxidative Phosphorylation," and neurodegenerative diseases such as Parkinson, Huntington, and Alzheimer (Fig. 4B). The GO analysis highlighted genes related to biological processes like "translation," cellular components like "ribosome," "extracellular exosome," "mitochondrion," "axon part," and molecular functions like "protein binding" and "structural constituent of cytoskeleton" (Fig. 4C). These GO categories were also previously described as enriched in the transcriptome of cultured axons (for review, see Farias et al. 2019).

To establish the protein-protein interactions (PPI) networks of the mRNA products identified in a mature 
axoplasm transcriptome, we used the STRING tool (v11.0, Szklarczyk et al. 2015). Out of the 1008 detected genes in the axoplasm sample, 789 were matched with the database and used to construct the PPI network (Supplemental Fig. S2A). This network, obtained with a high confidence mode (0.7), was enriched in interactions $(P$-value $<1 \times$ $10^{-16}$ ). The result shows two clusters formed by highly connected protein nodes, which combine proteins related to mitochondria and translation. Additionally, it can be seen that there are several connected nodes associated with the cytoskeleton, as well as proteasome and protein ubiquitination (Supplemental Fig. S2A). Interestingly, only mitochondrial encoded genes are highly abundant in comparison to median values of all genes detected or the three other nodes of interactors (Supplemental Fig. S2B).

We performed a deeper analysis of the mitochondrial, ribosomal and cytoskeleton categories, since these groups of proteins are interesting in the context of the axon neurobiology. First, we analyzed the mRNAs coding for mitochondrial proteins. Of the 1300 proteins categorized as mitochondrial in the MitoMiner database (Smith and Robinson 2019), 15\% (140 genes) were detected in the axoplasm transcriptome, while 92\% (1199 genes) were detected in the ventral root sample. The RNAs encoded by the mitochondrial DNA were up to eightfold more abundant in axoplasms in comparison with the ventral root, while the mRNAs encoded by the nuclear DNA were, on average, more abundant in the ventral root sample (Fig. $5 A)$. The difference between the abundance of RNAs encoding mitochondrial proteins encoded by mitochondrial or nuclear DNA was in agreement with that reported for cultured dorsal root ganglion (DRG) axons (Minis et al. 2014). Moreover, the abundance of mRNAs encoding for mitochondrial proteins encodes by the mitochondrial genome was several orders of magnitude greater than those codified by the nuclear genome (Supplemental Fig. S2B), in accordance with what was reported for in vitro axons (Minis et al. 2014; Nijssen et al. 2018). Since in our hands the mature axon would have the potential to locally synthesize only $15 \%$ (140 genes) of the mitochondrial proteome, we wonder if these RNAs, or the proteins they encode, possess any particular characteristic that leads to their localization in the axon. Recently, Fazal et al. (2019) developed APEX-seq technology to characterize the spatial organization patterns of RNA in the living cell. In the case of the outer membrane of mitochondria (OMM), associated mRNAs include those with mitochondrial and nonmitochondrial functions (Fazal et al. 2019). In our case, $17 \%$ of axonal RNAs (170/1008, Supplemental Table S3) are described as associated to mitochondria in the APEX-seq data set (APEX-OMM). Fiftynine of them code for mitochondrial proteins, leaving

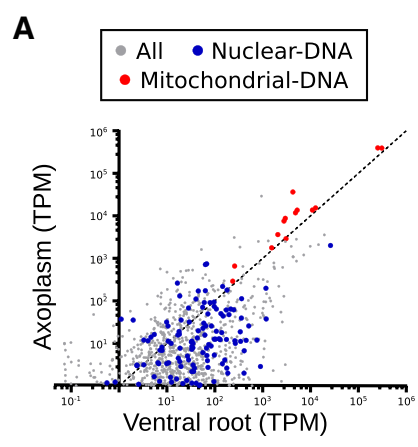

B

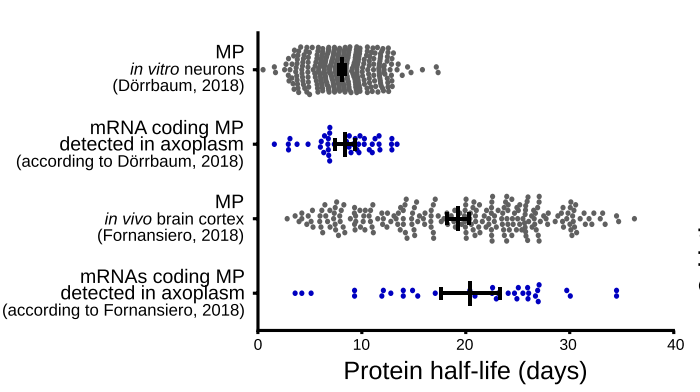

C

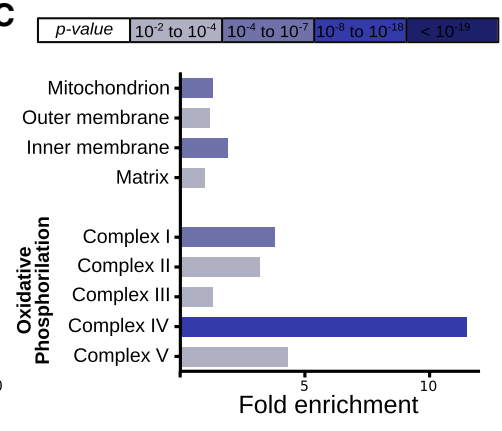

E

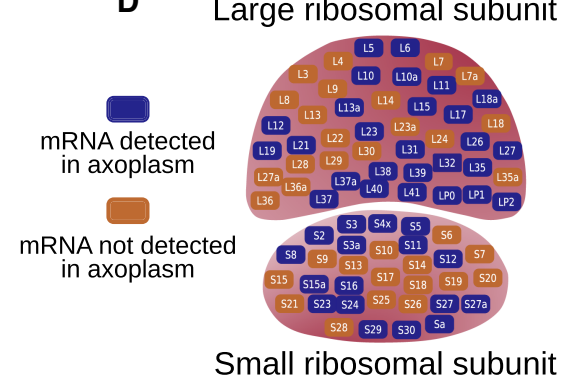

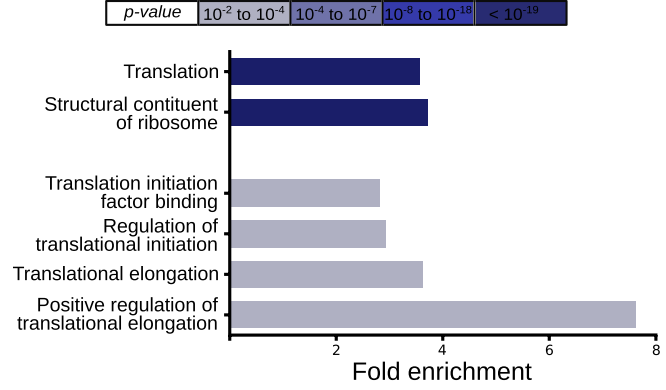

FIGURE 5. Mitochondrial and translation related genes detected in mature myelinated axon transcriptome. (A) Distribution of mitochondrial mRNAs in comparison to all the transcripts detected in both samples. Axoplasm ( $y$-axis) versus ventral root ( $x$-axis) mRNA expression levels of all transcripts detected (gray), nuclear encoded mitochondrial genes (blue) and mitochondrial DNA encoded genes (red). (B) Comparison of the half-life of axonally detected (blue dots) mitochondrial proteins (MP) mRNAs at average and $95 \% \mathrm{Cl}$ using data obtained for in vitro cultured neurons (Dörrbaum et al. 2018) and brain cortex in vivo (Fornasiero et al. 2018) (gray dots). (C) Gene ontologies related to mitochondria enriched in axoplasm transcriptome. (D) Scheme depicting the 44 specific ribosomal proteins that were detected in the axoplasmic transcriptome. (E) Gene ontologies related to translation enriched in axoplasm transcriptome. 
111 as candidates to use mitochondria for their transport. Interestingly, we detected 81 mitochondrial mRNAs present in axons and not present in the APEX-OMM data set. For these, a nonmitochondrial-dependent mechanism of transport may be occurring. On the other hand, we hypothesize that this may represent the capacity to assist the turnover of particular functions or processes or be related to different turnover rates. Using the half-life of mitochondrial proteins determined recently in neurons both in vitro (Dörrbaum et al. 2018) and in vivo (Fornasiero et al. 2018), we observed that the distribution of protein half-lives for our axonal mitochondrial mRNA ranged from very short (2-5 d) to longer half-lives (30 d). Globally, the mitochondrial proteins encoded by the mRNAs detected in axoplasm did not show an evident shorter lifetime compared with the total mitochondrial proteins studied (Fig. 5B). Interestingly, the axonal mRNAs coding for mitochondrial proteins are involved in key functions at the mitochondrial matrix and outer and inner membrane, being part of different respiratory chain complexes (Fig. 5C), as well as biological processes such as fission and fusion. These proteins are usually under heavy reactive oxygen species (ROS) modifications, and therefore it may be important to have local mechanisms to renew/repair their function while in transit or at final destinations.

Secondly, we analyzed the mRNAs encoding proteins related with translation processes. In the axoplasm sample, 44 mRNAs ( $50 \%)$ were detected out of all coding ribosomal proteins ( $\sim 80$ proteins), 27 from the large subunit, and 17 from the small subunit (Fig. 5D). Moreover, the axoplasm sample was enriched in GO terms related to translation initiation, and elongation, as well as to the regulation of these processes (Fig. 5E). The abundance of mRNAs coding for ribosomal proteins is variable, ranging from low to medium-high (Supplemental Fig. S2B). The localization of mRNAs coding for ribosomal proteins in axons has been widely reported previously (Willis et al. 2007; Taylor et al. 2009; Zivraj et al. 2010; Gumy et al. 2011; Saal et al.
2014; Briese et al. 2015; Rotem et al. 2017; Nijssen et al. 2018; Tóth et al. 2018). The presence of these mRNA raises the possibility that axons possess the capacity to use locally synthesized ribosomal proteins for the replacement of their damaged pairs, which would increase the half-life of the ribosomes. It is possible that nonribosomal functions of ribosomal proteins can be at play in the axon too.

Finally, we identified several mRNAs coding for cytoskeletal proteins (Supplemental Fig. S2A), including structural components and regulatory ones. The abundance of mRNAs coding for structural components of the cytoskeleton is variable, the neurofilament light subunit and tubulins subunits (Tuba1a, Tuba1b) mRNAs being the most abundant (Supplemental Fig. S2B).

In summary, our data show that mature myelinated axons are enriched for mRNAs related to cytoskeleton, translation, and oxidative phosphorylation. Thus, the mature myelinated axons have the capacity to locally maintain, at least in part, the cytoskeleton, the translation machinery, as well as the mitochondria, a key organelle for the correct function of the neuron.

\section{RT-qPCR validation of transcripts present in mature myelinated axons}

For the validation of the RNA-seq data we performed RT-qPCR of individual $(n=5)$ replicates for 13 genes (Fig. 6). The selected genes are expressed at high, moderate, and low levels in the axoplasm sample, and span several different cellular and molecular categories. High consistency between the RNA-seq and RT-qPCR results was found using linear regression analysis of the fold change of gene abundance in axoplasm vs. ventral root samples $\left(R^{2}=0.8670\right.$, Fig. $\left.6 \mathrm{~A}\right)$, indicating that the data produced through RNA-seq is reliable. As shown in Figure 6B, the mRNA coding for the synaptic protein Snca ( $\alpha$-synuclein), the member of the Src signaling pathway Skap2 (Src kinase associated phosphoprotein 2) and the endoplasmic
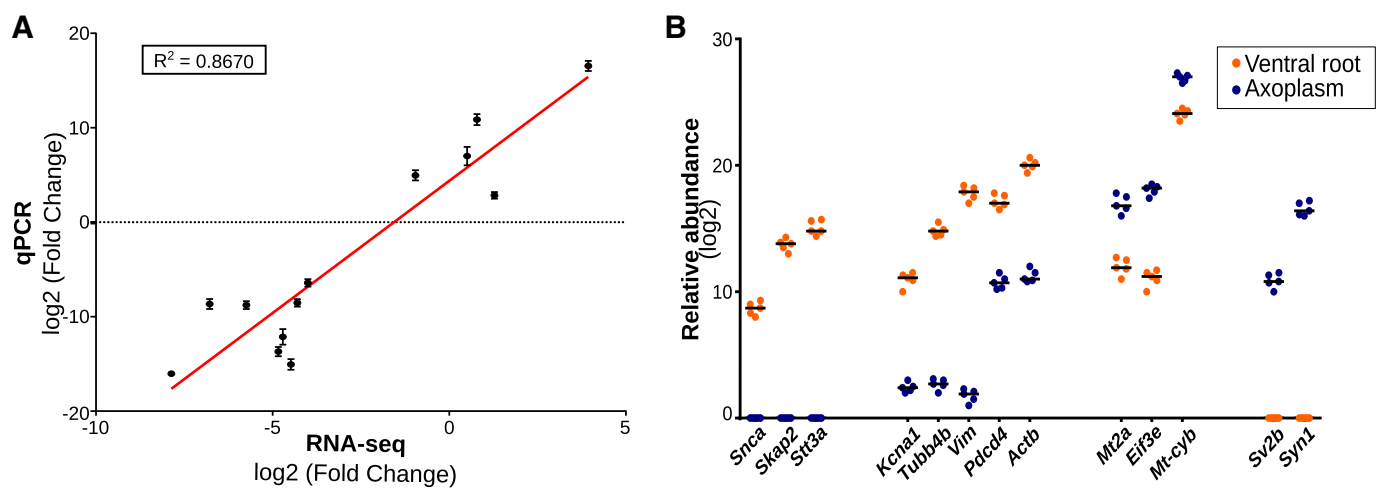

FIGURE 6. Validation of RNA-seq data by RT-qPCR. (A) Correlation of gene expression fold change (axon vs. ventral root) obtained by RT-qPCR ( $y$-axis) and RNA-seq (x-axis). All RT-qPCR data was collected from five biological replicates (mean and standard deviation values are represented). Statistical goodness of fit value is provided (red). (B) Expression analysis by RT-qPCR of 13 mRNAs with different patterns of localization and expression are shown. Note the minimal dispersion among the biological replicas (coefficient of variation [\%]: 6.20 20.58 ). 
reticulum protein Stt3a (STT3 oligosaccharyltransferase complex catalytic subunit A) were not detected in the axoplasm but were detected in ventral root samples. The mRNAs coding for cytoskeletal proteins Tubb4b (tubulin beta 4B class IVb), Vim (vimentin), and Actb ( $\beta$-actin), the potassium channel Kcna1 (potassium voltage-gated channel subfamily A member 1), and the translation inhibitor $\mathrm{Pdcd} 4$ (programmed cell death 4), were detected in both samples, with high abundance in ventral root samples. Conversely, the metallothionein protein Mt2a (metallothionein 2A), the translation factor Eif3e (eukaryotic translation initiation factor 3 subunit E), and the component of the complex III of mitochondrial electron transport Mtcyb (mitochondrially encoded cytochrome B) were detected with high abundance in axoplasm samples relative to ventral samples. Finally, the mRNA coding for synaptic vesicle protein Sv2b (synaptic vesicle glycoprotein $2 B$ ) and the synaptic protein Syn 1 (synapsin I) were detected only in axoplasm samples (Fig. 6B).

With these results we can affirm that the pooling of samples and the linear amplification of RNA did not significantly affect the abundance levels of mRNAs, since there is a high correlation with the data obtained in RNA-seq analysis (pooling of five samples, linear amplification of RNA and then sequenced) and RT-qPCR performed in unamplified RNA from individual samples.

\section{In vivo motor axon transcriptome shares a core group of genes with in vitro axonal transcriptomes}

To assess which RNAs are found in both mature myelinated axons and culture growing axons, we compared our data with a published axon data set derived from primary embryonic DRG neurons (Minis et al. 2014), primary embryonic motor neurons (Briese et al. 2015), neurons differentiated from mouse embryonic stem cells (mESC) (Zappulo et al. 2017), and motor neurons derived from mESC (Nijssen et al. 2018). For this, we reanalyzed all the data sets from scratch by performing the same protocol analysis to avoid bias. Of the 758 genes detected in mature myelinated axons (conformed only by the orthologs between rat and mouse), 95.5\% have been reported for in vitro axons by previous work (Fig. 7A). In addition, almost 40\% (300 genes, Supplemental Table S4) were detected in all compared axon data sets. The latter can be considered as a core set of genes needed in axons of different types (sensory or motor) or in various differentiation conditions (mature or in active growth). The PPI network obtained with a high confidence mode $(0.7)$ is enriched in interactions $\left(P\right.$-value $\left.<1 \times 10^{-16}\right)$. The proteins codified by these mRNAs are mainly related to translation, mitochondria, and cytoskeleton (Fig. 7B). On the other hand, a small group of mRNAs were only detected in mature axons (Supplemental Table S4). It is important to note the large difference in the number of detected genes between our set and the in vitro axon data sets, especially in the case of DRG neurons (Minis et al. 2014), primary embryonic motor neurons (Briese et al. 2015), and neurons differentiated from mESC (Zappulo et al. 2017). The biological meaning of such a large number was discussed in the corresponding manuscripts originating from each data set, but it could also arise from cross contamination between somatodendritic and axonal compartments, as suggested by the Hedlund group (Nijssen et al. 2018).
A

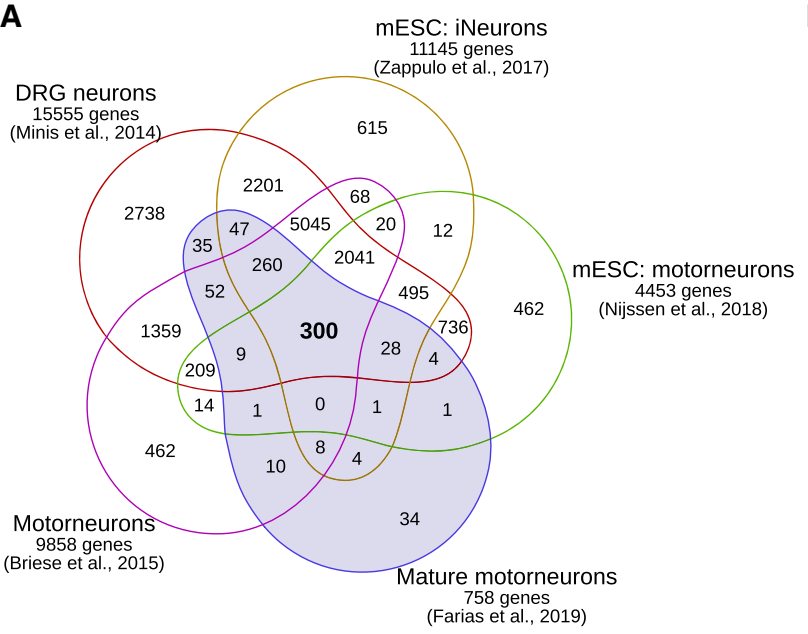

B

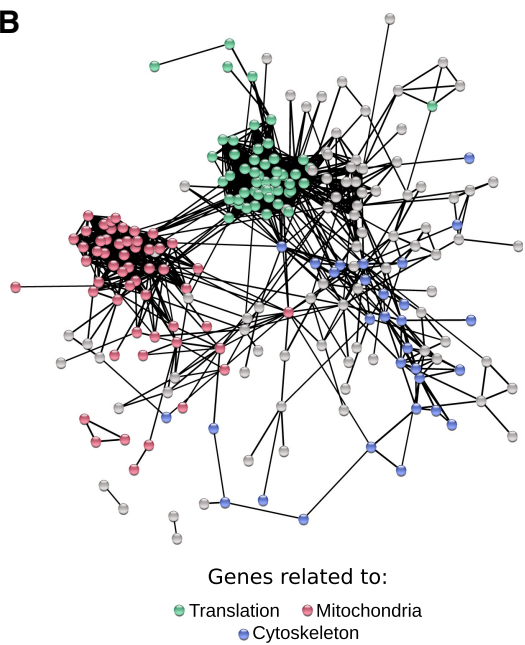

FIGURE 7. Comparison of axonal transcriptome data sets reveals a group of core genes present in both in vitro growing in culture and microdissected mature axons. (A) Venn diagram performed to compare our data with published axon data set derived from primary embryonic DRG neurons (Minis et al. 2014), primary embryonic motor neurons (Briese et al. 2015), neurons differentiated from embryonic stem cells of mouse (mESC) (Zappulo et al. 2017) and motor neurons derived from mESC (Nijssen et al. 2018). (B) Protein-protein interactions network of the core genes (300 genes) identified in different types of axons using the STRING database. These genes are highly connected and are related to mitochondria (red), translation (green), and cytoskeleton (blue). Not connected genes are not shown. 
Additionally, several research groups have delved into the transcriptome characterization of different neuronal subcompartments, such as growth cones (Zivraj et al. 2010), synaptic neuropil in the hippocampus (Cajigas et al. 2012) or, more specifically, the RNA being translated in cortical synaptosomes (Ouwenga et al. 2017) or in retinal ganglion cell (RGC) axons terminals (Shigeoka et al. 2016). In the latter, the axonal translatome of distal axons in vivo at different time points during the assembly of visual circuits, including adulthood, was reported. One of the main findings was that the axonal translatome is composed of two parts, one constitutive and the other specifically regulated according to the needs of each stage (Shigeoka et al. 2016). When comparing the adult axonal translatome with our fully differentiated peripheral motor axon transcriptome, we found 139 genes in common, mostly related to translation, mitochondrion, cytoskeleton and axonal part (Supplemental Table S4). Moreover, a new platform which combines fluorescence sorting with biochemical fractionation was recently developed in order to purify fluorescently labeled synaptosomes (fluorescence-activated synaptosome sorting [FASS]) (Luquet et al. 2017). Using this platform, Schuman and colleagues determined the resident mRNA population at adult mouse presynaptic boutons, identifying 468 transcripts enriched in the sorted synaptosomes (Hafner et al. 2019). Of those, in our axonal preparation, we observe 77, mainly coding for ribosomal proteins (29 transcripts) and translation factors (five transcripts), molecular motors associated with the cytoskeleton (five transcripts), and mitochondrial proteins (four transcripts) (Supplemental Table S4). Surprisingly, we noticed that only one presynaptic protein, Rims2 (regulating synaptic membrane exocytosis 2), was common to both data sets. However, when comparing our axonal transcriptome with the genes associated with the ontological term of presynapse (GO: 0098793), we observed 37 genes in common. Among these, typical synapse proteins such as Pclo (Piccolo), Sept4 (Septin 4), Syn1 (Synapsin I), and Snap25 (Synaptosomal-associated protein 25) were observed (Supplemental Table S4). Additionally, we want to underscore that the abundance levels for these mRNAs were high, ranging from 3.5 to 272 TPM. This highlights the potential for translation of synaptic proteins in the axon, far away from the cell body and the synaptic bouton.

In summary, these results reveal an axonal core molecular signature, found in in vitro and in vivo axons, in different growth conditions and states of differentiation.

\section{DISCUSSION}

RNA localization and local protein synthesis are mechanisms that confer spatial and temporal control of the proteome. The role of these mechanisms in the axonal compartment of neurons has been widely studied, with important recent advances (for reviews, see Glock et al. 2017;
Cioni et al. 2018; Farias et al. 2019). In the last 10 yr, transcriptomic approaches have been used to characterize the RNA pool localized in axons grown in vitro. This was possible thanks to advances in neuronal cell culture techniques, allowing for the separation of neuronal soma and other cell types from axons (for reviews, see Jadhav et al. 2015; Neto et al. 2016). These results provided valuable evidence regarding the capacity to synthesize proteins locally in the axonal domain. However, the transcriptome of mature myelinated axons is still largely unknown due to difficulties in obtaining axonal content from this type of sample. The axon microdissection method, developed originally by Koenig (1979), allows researchers to obtain axoplasm whole-mounts from different types of axons including the motor axons derived from medullary ventral roots. The method is based on the axon behavior as a viscoelastic gel due to the abundant content of neurofilaments (Gilbert 1975). The tensile strength that is required for isolation depends on axon diameter and the content of neurofilaments (Gilbert 1975; for review, see Koenig 2009). Zinc denaturation transforms the axonal viscoelastic gel into a plastic solid, which enhances tensile strength, and permits the isolation of axoplasmic whole mounts from small diameter fibers (for review, see Koenig 2009). This transformation is based on the zinc-dependent inhibition of the endogenous calcium activated protease which degrades the neurofilament protein in the presence of elevated calcium concentration (Gilbert 1975; Frankel and Koenig 1978). The microdissection method was widely used by Koenig's and our group to characterize translation machinery components of axoplasm, mainly those of the periaxoplasmic ribosome plaques (PARPs) (Koenig and Martin 1996; Koenig et al. 2000; Sotelo-Silveira et al. 2004, 2008; Kun et al. 2007; Calliari et al. 2014). The procedure maintains RNA integrity, as demonstrated either by observing the electrophoretic profiles of total RNA extracts from Mauthner axons (Koenig 1979) or by in situ hybridization in axoplasmic whole-mounts (Sotelo-Silveira et al. 2008; Calliari et al. 2014). Here, we modified the axon microdissection technique to obtain pure axoplasm derived from lumbar ventral roots (Fig. 1A,B) in order to characterize the transcriptome of mature motor axons.

The observation of isolated axoplasms, both by fluorescence microscopy (Fig. 1D) and scanning electron microscopy (Fig. 1E), showed that the method allows for the recovery of axoplasm with minimal myelin contamination at the axon surface. Furthermore, a high-sensitivity molecular quality control was developed, quantifying by RT-qPCR the relative abundance of glial and neuronal markers in axoplasms and ventral roots samples. The glial markers decreased their abundance in axoplasm extracts in comparison with ventral root samples between 15-fold for Mbp mRNA and more than 35-fold for Pmp22 and Mag mRNAs (Fig. 2B). The smaller decrease of the Mbp mRNA abundance in the axoplasm samples could be 
explained by the specific pattern of localization that this mRNA has in the glia. We observed Mbp mRNA localized to the axon-glial contact sites in ventral roots sections (Fig. 2D-D'), as it was described for oligodendrocytes (White et al. 2008), making this mRNA more likely to be carried over when the axoplasm is translated out of its ensheathment. This is in agreement with an RNA-seq study of central nervous system myelin, where Mbp mRNA was found enriched ten times more than Pmp22 and Mag mRNA in myelin extracts vs. whole brain cortex (Thakurela et al. 2016). Although these indicate that the axoplasm may have minimal internal mesaxon glial contaminants, the preparation is highly enriched in axonal mRNAs.

As mentioned above, axons in culture have been the main source of transcriptome data in the field. Since the amount of RNA contained within the axons is typically low, it is necessary to collect and pool many samples (Minis et al. 2014; Zappulo et al. 2017) or use an axonal field in culture and apply steps of RNA amplification (Briese et al. 2015) for RNA-seq library construction. The need of linear RNA amplification was also present in the case of microdissected axons, where five biological replicates of axoplasm samples were pooled in order to reach the minimum input requirement. The number of detected genes in the mature myelinated axons was 1008 (Fig. 3A), significantly lower than that described for in vitro axons. It is important to note that in the ventral root samples 11,333 genes were detected (Fig. 3A), having performed the same procedure (its molecular biology and the corresponding bioinformatics) to avoid bias. For both samples, saturation was reached globally and specifically in the protein-coding category (Fig. 3B). Through ranking (Fig. 3C) and correlation analysis (Fig. 3D), it can be seen that the axoplasm sample is not merely the product of a dilution of transcriptome contained in the whole ventral root sample. The latter is clearly reflected by the top 50 RNAs coming from each fraction (Fig. 3E). Although there are genes in common, like mitochondrial genes (likely belonging to axonal mitochondria) and some ncRNAs and pseudogenes, the groups that were not shared determine that axonal and ventral root RNA extracts are different. Within the top 50 most abundant genes in the ventral root there were genes coding for myelin proteins (such as Mbp, Mag, Pmp22, S100b, Mpz). These genes were not only absent in the 50 most abundant genes found in the axoplasm sample, but were also detected at a very low abundance (Fig. 3E). These results, taken together, show, at a genome wide scale, that the axon microdissection procedure permits an efficient purification of axoplasm RNA with very low amounts of glial components, especially myelin. Additionally, the individual study of unamplified RNA from axons by RT-qPCR shows that the method is very reproducible (Figs. 2, 6), exhibiting very low dispersion in five independent biological replicas of unamplified RNA.
The mature myelinated axon transcriptome is composed of RNA of different biotypes, including protein coding, ncRNA, IncRNA and pseudogenes (Fig. 4A). The abundance of mitochondrial rRNAs in the axon is almost twice that of the ventral root, similar to what has been described for axons in culture when compared to the somatodendritic compartment (Briese et al. 2015). Additionally, the axoplasm sample is enriched in genes related to neurodegenerative diseases (Fig. 4B). While this may be mainly due to the presence of genes encoding for oxidative phosphorylation proteins, other key genes of the canonical pathways of Alzheimer's (Gapdh, Calm1, Gsk3b, and Ppp3ca), Parkinson's (S/c25a4 and Uch/1), and Huntington's (Tbp, Polr2a, Ap2m1, Slc25a4, Sod1, and Sod2) were detected. Furthermore, transcripts with functions related to protein synthesis and cytoskeleton were overrepresented in axoplasm compared to the ventral root transcriptome (Fig. 4C).

The PPI network of the axoplasm transcriptome showed a high prevalence of proteins related to mitochondria, translation and cytoskeleton, forming highly connected clusters (Supplemental Fig. S2A). If the mitochondrial mRNAs were to be locally translated in the axon, they would account for $\sim 15 \%$ of the mitochondrial proteome. Globally, the mRNAs encoded by the mitochondrial genome were more abundant in axoplasms in comparison with the ventral root sample, while those encoded by nuclear DNA were, on average, more abundant in the ventral root sample (Fig. 5A). Additionally, in the axoplasm sample, the mRNAs encoded by the mitochondrial genome were more abundant by several orders of magnitude in comparison to those encoded by the nuclear genome (Supplemental Fig. S2B), as reported by others for in vitro axons (Minis et al. 2014; Nijssen et al. 2018). The proteins codified by those mRNAs are related to different processes which take place in mitochondria, like oxidative phosphorylation (Fig. 5C), fusion and fission (Opa1 and Ddhd1), and ribosomal proteins of mitochondria (Mrp/18, Mrps26, and Mrp/35). Although we did not find that proteins encoded by the mRNAs present in axoplasm have a shorter half-life (Fig. 5B), the genes found are usually the main targets of reactive oxygen (ROS) and nitrogen species (RNS) resulting in mitochondrial dysfunction. This is the case of Glyceraldehyde-3-phosphate dehydrogenase (Gapdh), Aconitase (Aco2), and members of the oxidative phosphorylation complex I, II, III, IV, and V (for reviews, see Brown 2001; Quijano et al. 2016). Therefore, we think that local renewal of these key components after damage can be paramount to maintaining mitochondrial functionality while in transit or at final destinations.

The mRNAs encoding ribosomal proteins have been reported in several of the studies of axonal transcriptome (Willis et al. 2007; Taylor et al. 2009; Zivraj et al. 2010; Gumy et al. 2011; Saal et al. 2014; Briese et al. 2015; Rotem et al. 2017; Nijssen et al. 2018; Tóth et al. 2018), 
and recent work provides evidence of its local synthesis in in vitro (Shigeoka et al. 2016) and in vivo (Cagnetta et al. 2018) axons. The function of those proteins locally synthesized in axons opens an interesting debate, since this implies ribosome assembly far away from the classical assembly factory, the nucleolus (for reviews, see FromontRacine et al. 2003; Peña et al. 2017). Recent work provides evidence of incorporation of locally synthesized ribosomal proteins in cytosolic ribosomes present in axons (Shigeoka et al. 2019). Through this mechanism, axons would be able to repair or modificate ribosomes on-site, extend their halflife or change the targets to be translated (Shi et al. 2017). A possible alternative is that extraribosomal functions of ribosomal proteins (for review, see Warner and Mclntosh 2009) can be functional in the axon space. Regardless of what the final word on the matter is, we detected more than half of the mRNAs coding ribosomal proteins of both subunits in axonal extracts (Fig. 5D). Some of those proteins (rpS3A, rpS4, rpS12, rpS27A, rpLP0, rpL13A, $r p L 18 A, r p L 21, r p L 27, r p L 31)$ were described to be locally synthesized and incorporated on cytosolic ribosomes of RGCs axons (Shigeoka et al. 2019). Interestingly, we detected other mRNAs coding proteins associated with ribosome biogenesis and assembly, and regulation of the process of translation (Fig. 5E).

The mature myelinated axons also possess mRNAs coding for cytoskeletal and proteasome proteins (Supplemental Fig. S2A). Local translation of cytoskeleton proteins could confer to the axon the ability to remodel or maintain its structural components (Sotelo-Silveira et al. 2000). In the case of $\beta$-actin, it was described that its local synthesis in growing axons contributes to the stabilization of new branches, and most likely helps in branch emergence (Wong et al. 2017). Additionally, the role of protein degradation was reported in injured axons both in vitro and in vivo (for review, see Gumy et al. 2010). The presence of mRNAs encoding proteasomal proteins could provide a rapid mechanism to rapidly respond to an injury.

With the purpose of identifying a group of core genes present in axons of different types of neurons and differentiation conditions, we compared our data with published data obtained for in vitro isolated axons (Minis et al. 2014; Briese et al. 2015; Zappulo et al. 2017; Nijssen et al. 2018). Generally, one focus on these studies was the enriched axonal mRNAs as derived from the comparison of axons versus the somatodendritic compartment, instead of the total RNAs detected in axons. This strategy excludes from the analysis RNAs that are known to be present in axons and whose local synthesis and functions have been demonstrated, such as $\beta$-actin (Leung et al. 2006; Yao et al. 2006; Donnelly et al. 2011; Willis et al. 2011; Wong et al. 2017). Therefore, to perform the comparison between our transcriptome and the published data, we reanalyzed the data sets from raw sequences. Ninety five percent of RNAs detected in the mature myelinated motor axons was previously detected at in vitro growing axons (Fig. 7A). Furthermore, 40\% were detected in all the axons analyzed (Supplemental Table S4). These RNAs codified for proteins with functions related to mitochondria, ribosomes and the cytoskeleton (Fig. 7B). Although mRNA complexity appeared to be lower than that observed in several in vitro studies (Minis et al. 2014; Briese et al. 2015; Zappulo et al. 2017), it is worth noting that the total number of RNA detected in our preparation is comparable to what Hedlund and colleagues reported recently (Nijssen et al. 2018). This agreement in the number of detected RNA species in vitro and in vivo, appears to be supported in our case since we are utilizing zinc solution as a fixative, which preserves protein complexes and RNA in axons (Koenig 1979; Sotelo-Silveira et al. 2008; Calliari et al. 2014) and in many other preparations (Lykidis et al. 2007; Hadler-Olsen et al. 2010; Jensen et al. 2010), but we cannot rule out the loss of more soluble RNAs.

On the other hand, we perform comparisons with data sets derived from more specific neuron subdomains: the translatome of axon terminals derived from adult mouse RGCs (Shigeoka et al. 2016) and the transcriptome of adult mouse presynaptic boutons (Hafner et al. 2019). The former is a pioneering work in the area, showing which mRNAs are being translated in axonal terminals at different development stages, even in adults (Shigeoka et al. 2016). The latter describes the transcriptome of adult presynaptic boutons and demonstrates that local protein synthesis is a regular feature of pre- and post-synapse under basal conditions, and that in the face of different excitatory or inhibitory stimuli, a differential local response occurs in these compartments to modify the local proteome. Interestingly, the two data sets mentioned above as well as our mature motor axon transcriptome are enriched in mRNAs encoding translation, cytoskeleton and mitochondria related proteins. Although in our data set we found mRNAs encoding for synapse-related proteins in good abundance, the number did not reach a threshold to be considered as enriched as it was reported for terms such as synaptic transmission by Shigeoka et al. (2016) and presynaptic active zone by Hafner et al. (2019). The latter could indicate a differential localization between the axon and the axon terminals, with RNAs in transit to the synaptic boutons showing in low amounts in the axon.

Knowing the mechanisms of RNA transport that localize RNAs in the axonal domain is of key importance, since transport failure is associated with several neurodegenerative diseases (for reviews, see Ikenaka et al. 2012; Costa and Willis 2018). In the case of mitochondria, APEX-seq data (Fazal et al. 2019) provided a reference of mRNA associated with its outer membrane (APEX-OMM), there, some had mitochondrial function but others have diverse tasks. Only $17 \%$ of the axonal transcriptome was present in the APEX-OMM data set. This means that the transport mechanism that may use mitochondria as carriers only 
applies to almost one fifth of the mRNA localized in our preparation. Interestingly, not all the mitochondrial mRNA observed in the axon is in the APEX-OMM list. Additionally, about a hundred mRNAs not related to mitochondrial function may be localized through association to mitochondria. In addition to the classical mechanisms of RNA transport through RBP associated with the cytoskeleton, it has recently been described that RBPs can be associated with lysosomes (Liao et al. 2019) or mobile endosomes, in turn providing sites for local axonal translation (Cioni et al. 2019). Further studies will be required to understand the mechanisms involved in the transport and localization of RNA in mature axons.

In summary, we developed a modification of an axon microdissection technique that makes it possible to obtain pure axoplasm in quantities enough to isolate RNA and analyze it by sequencing. This was used to characterize the RNA species of a fully differentiated and myelinated motor axon. In resting conditions, these motor axons appear to have a core group of RNAs involved in protein synthesis, cytoskeleton, and mitochondria. However, it is clear that this is a picture of a basal state for RNAs that may have local functions in the area studied or also be in transit to final destinations. Regarding the latter, this approach would be useful to capture RNA in transit in different physiological conditions, or to study the axonal processes that occur in models of neurodegenerative diseases such as ALS and spinal muscular atrophies (SMA) in vivo.

\section{MATERIALS AND METHODS}

\section{Animals \\ Sprague-Dawley male adult rats $(10 \mathrm{mo})$ were obtained from the animal facility at the Instituto de Investigaciones Biológicas Clemente Estable (IIBCE, Montevideo, Uruguay), maintained on a 12-h light-dark cycle, with food and water provided ad libitum. All experimental procedures were conducted in strict accordance with the Institution's Comité de Ética en el Uso de Animales (CEUA-IIBCE) under law 18.611 of the República Oriental del Uruguay. The specific protocol was approved by the CEUA- IIBCE (experimental protocol $\left.N^{\circ} 005 / 05 / 2012\right)$. The animals were anesthetized by an intraperitoneal injection of $100 \mathrm{mg} / \mathrm{Kg}$ ketamine and $20 \mathrm{mg} / \mathrm{Kg}$ xylazine, and then euthanized by decapitation. \\ Isolation of axoplasmic whole-mounts from myelinated ventral root fibers}

Isolation of axoplasmic whole-mounts was performed according to Koenig (1979), Koenig and Martin (1996), Koenig et al. (2000), Sotelo-Silveira et al. (2004, 2008), and Calliari et al. (2014) with the following modifications. Lumbar spinal ventral roots were dissected from euthanized rats. The tissue (see Fig. $1 \mathrm{~A}, \mathrm{~B})$ was suspended in a modified gluconate-substituted calcium-free Cortland salt solution (Koenig and Martin 1996) contain- ing $132 \mathrm{mM}$ Na-gluconate, $5 \mathrm{mM} \mathrm{KCl}, 20 \mathrm{mM}$ HEPES, $10 \mathrm{mM}$ glucose, $3.5 \mathrm{mM} \mathrm{MgSO}_{4}$, and $2 \mathrm{mM}$ EGTA, pH 7.2, stored at $4^{\circ} \mathrm{C}$. A ventral root, $3-5 \mathrm{~mm}$, was immersed in a solution of $30 \mathrm{mM}$ zinc acetate, $0.1 \mathrm{M}$ Tricine, $\mathrm{pH} 4.8$, for 10 min for denaturation. Then, it was transferred to a $35 \mathrm{~mm}$ plastic culture dish containing an axon "pulling" solution in which axoplasm was translated out of its myelin sheath with a pair of micro-tweezers \#5 (Fig. 1B,ii). The "pulling" solution contained $40 \mathrm{mM}$ aspartic acid, $38 \mathrm{mM}$ Tris, $1 \mathrm{mM} \mathrm{NaN}_{3}$, and $0.02 \%$ Tween 20 to reduce surface tension, pH 5.5 (Koenig et al. 2000; Sotelo-Silveira et al. 2004, 2008; Calliari et al. 2014). The pulling generates a spray of axons (about 30 axon segments) that can be condensed into a bundle, being easier to process in further steps. Each spray was condensed into a compact bundle by briefly drawing the spray out of solution except for one end. By drawing the bundle in and out of solution several times (Fig. 1B,iii) we eliminate the remaining pieces of myelin on the surface of the axon. Isolated axoplasmic whole-mount bundles were attached with the aid of eyebrow hair tools to coverslips coated with 1\% (3-aminopropyl) triethoxysilane (Sigma-Aldrich) in ethanol (Fig. 1B,iv). The tissue that remains still in the end of the spray was removed by a scalpel (Fig. 1B,v). Additionally, three washes with fresh "pulling" solution were performed to further decrease any possible contamination (Fig. 1B,vi). The isolated axoplasmic whole-mounts were removed from the coverslip with the aid of eyebrow hair tool, placed in the cap of an Eppendorf $1.5 \mathrm{~mL}$ tube in $20 \mathrm{ul}$ of "pulling" solution and stored at $-80^{\circ} \mathrm{C}$ until RNA extractions were performed (Fig. 1B,vii).

\section{Imaging of F-actin cortical layer and lipid content of microdissected axons}

The axoplasm whole-mount was obtained as described above until the step of attachment to the coverslip. Before attachment, axoplasmic whole-mounts were unraveled for better visualization. Then, they were immediately incubated with Alexa Fluor 488 phalloidin (working dilution 1/400, Invitrogen, ThermoFisher Scientific) and Nile Red (working dilution 1/1000 from a solution of $100 \mu \mathrm{g} / \mathrm{mL}$ in acetone, Invitrogen, ThermoFisher Scientific) $20 \mathrm{~min}$ at room temperature in PBS buffer. The material was mounted with ProLong Gold Antifade (Invitrogen, ThermoFisher Scientific) and stored at $4{ }^{\circ} \mathrm{C}$ light protected until visualization. A laser confocal microscope LSE ZEISS 800 was used with $40 \times$ (air, NA 0.95) and $63 \times$ (oil, NA 1.4) objectives. The stacks were always taken at ideal um number between each $z$ plane. The software to control the microscope and take the images was the ZEN Blue version 2.3.

\section{smFISH procedure}

\section{Tissue sections}

Fresh ventral roots were collected, gently straightened, and immersed in fixative solution (4\% paraformaldehyde in PHEMDEPC buffer, $25 \mathrm{mM}$ HEPES, 60mM PIPES, $10 \mathrm{mM}$ EGTA, $2 \mathrm{mM} \mathrm{MgCl}_{2}, \mathrm{pH}$ 7.2) for $1 \mathrm{~h}$ with stirring at room temperature. After three washes of 10 min each in PHEM-DEPC solution, the tissue was cryoprotected in 15\% sucrose solution (in PHEM-DEPC) for $24 \mathrm{~h}$ at $4^{\circ} \mathrm{C}$ and then $30 \%$ for another $24 \mathrm{~h}$. The pieces were 
placed in silicone rubber mods and embedded in the tissue freezing medium CryoGlue (SLEE Medical) and stored at $-80^{\circ} \mathrm{C}$. Frozen blocks were sectioned parallel to the longitudinal axis at $10 \mu \mathrm{m}$ thickness using a SLEE cryostat. Sections were collected onto Poly-L-lysine (Sigma-Aldrich) coated slides and stored at $-20^{\circ} \mathrm{C}$.

\section{In situ hybridization}

Custom Stellaris FISH Probes were designed against Nefl and Mbp by utilizing the Stellaris FISH Probe Designer (Biosearch Technologies) available online at www.biosearchtech .com/support/tools/design-software/stellaris-probe-designer. The ventral roots slices were hybridized with the Stellaris FISH Probe set labeled with Quasar570 and Quasar670 (Biosearch Technologies) (for Nefl and Mbp probes, respectively), following the manufacturer's instructions with some modifications. Briefly, tissue permeabilization was achieved by incubating the tissue with $0.5 \%$ Triton X-100 in PBS-DEPC, 20 min at room temperature. Excess detergent was removed by successive washes with PBSDEPC $(3 \times 10 \mathrm{~min})$. The tissue was immediately incubated in Wash Buffer A (10\% formamide [Sigma-Aldrich] in Stellaris RNA FISH Wash Buffer A [Biosearch Technologies]) for 5 min. Then, $200 \mu$ of Hybridization Solution (10\% formamide in Stellaris RNA FISH Hybridization Buffer [Biosearch Technologies]) was added to each slide, with each probe set at a final concentration of 250 $\mathrm{nM}$. The slides were place in a humidified chamber in the dark at $37^{\circ} \mathrm{C}$ for $4 \mathrm{~h}$. Each sample was washed with Wash Buffer A for $30 \mathrm{~min}$ in a humidified chamber at $37^{\circ} \mathrm{C}$. A second wash was performed, in this case with Wash Buffer A with DAPI (100 ng/mL) and AlexaFluor 488 phalloidin (Invitrogen, ThermoFisher Scientific) and left to incubate at $37^{\circ} \mathrm{C}$ for $30 \mathrm{~min}$. A final wash with Wash Buffer B (Biosearch Technologies) was performed. The samples were then mounted with Vectashield Mounting Medium (Vector Laboratories), covered by $22 \mathrm{~mm} \times 22 \mathrm{~mm}$ No. 1 coverslips, sealed with nail varnish and immediately imaged.

\section{Image acquisition}

Imaging was performed on a custom-made inverted single-molecule fluorescence microscope built around a commercial microscope frame (Olympus IX73). The microscope was equipped with an EM-CCD camera (Andor iXon Ultra 897) with an effective pixel size on the sample of $118 \mathrm{~nm}$. A 1.30 NA oil immersion objective (Olympus UPLSAPO 60x) was used.

\section{Axoplasmic whole-mounts processing for scanning electron microscopy}

For scanning electron microscopy (SEM) analysis, the axoplasm attached on glass coverslips were fixed overnight in 2,5\% glutaraldehyde in $0.1 \mathrm{M}$ phosphate buffer saline $\mathrm{pH} 7.2$ (PBS) at $4^{\circ} \mathrm{C}$. After that, axoplasms were washed in PBS $(5 \times 5 \mathrm{~min})$, dehydrated through a graded $(25,50,75,95,100 \%)$ ethanol-water series, transferred to acetone $2 \times 10 \mathrm{~min}$. Then, the samples were submitted to critical point drying with $\mathrm{CO}_{2}$ in a DPC-1 Denton Vacuum Critical Point Drying apparatus. Dried samples were affixed to aluminum stubs with carbon tape and sputter-coated with gold in Deskll Denton Vacuum. Samples were analyzed in high vacuum in a Jeol-5900 LV SEM operated at an accelerating voltage of $20 \mathrm{kV}$.

\section{RT-qPCR for quality control and validation of RNA-seq}

\section{RNA extraction from axoplasm whole-mounts}

For axoplasmic samples, RNA extraction was performed with RNAqueous-Micro Total RNA Isolation Kit (Ambion, Invitrogen, ThermoFisher Scientific), a kit designed to obtain RNA from as little as 10 laser capture microdissected sections. First, axoplasm samples were centrifuged at maximum speed, and the buffer removed very carefully. The procedure for laser capture microdissection (LCM) was used for all the samples, with some modifications. Briefly, $100 \mu \mathrm{L}$ of lysis buffer was added to the pellet of axoplasms and incubated at $42^{\circ} \mathrm{C}$ for $5 \mathrm{~min}$. Then, $3 \mu \mathrm{L}$ of LCM additive and $129 \mu \mathrm{L}$ (1.25 volumes) of $100 \%$ ethanol was added to the mixture to recover large and small RNAs. The lysate/ethanol mixture was loaded onto a Micro Filter Cartridge Assembly and centrifuged for $1 \mathrm{~min}$ at $10,000 \mathrm{~g}$. Afterward, 180 $\mu \mathrm{L}$ of wash solution 1 were added, and the mixture was centrifuged again for $1 \mathrm{~min}$ at $10,000 \mathrm{~g}$. Wash Solution $2 / 3(180 \mu \mathrm{L})$ was added, and the mixture was centrifuged for $30 \mathrm{sec}$ at $13,000 \mathrm{~g}$ and we repeated the wash one more time. The flowthrough was discarded and the Micro Filter Cartridge was centrifuged for another minute at $13,000 \mathrm{~g}$ to dry the filter. The Micro Filter Cartridge was transferred into a Micro Elution Tube, and 8 $\mu \mathrm{L}$ of preheated Elution Solution were added. The mixture was left at room temperature for $5 \mathrm{~min}$ and then centrifuged for $1 \mathrm{~min}$ at $13,000 \mathrm{~g}$. Subsequently, treatment with DNase was performed, adding 1/10 volume of $10 \times$ DNase I Buffer and $1 \mu \mathrm{L}$ of DNase I, and incubating the DNase reaction for $5 \mathrm{~min}$ at $37^{\circ} \mathrm{C}$. To inactivete the DNase, 1/10 volume of DNase Inactivation Reagent was used. After centrifugation of the reaction for $1.5 \mathrm{~min}$ at maximum speed to pellet the DNase Inactivation Reagent, the RNA was transferred to a fresh RNase-free tube and stored at $-80^{\circ} \mathrm{C}$ until further processing.

\section{RNA extraction from ventral root samples}

The RNA from ventral roots were obtained using TRI Reagent (Sigma-Aldrich), following the recommendations of the manufacturer. Quality and quantity of RNA was evaluated using spectrophotometry (Nanodrop 1000, Thermo Scientific) and fluorimetry (Qubit 2.0 and RNA HS Assay kit, Invitrogen, ThermoFisher Scientific). To be in comparable concentration as the RNA extracted from axons, each ventral root RNA was diluted down to $500 \mathrm{pg}$ and then reisolated with the RNAqueous-Micro Total RNA Isolation Kit, following the procedure detailed above.

\section{$R T-q P C R$}

For quality analysis of axoplasm samples and confirmative RT-qPCR assays, EXPRESS qPCR SuperMix (Life Technologies, ThermoFisher Scientific) was used according to the manufacturer's instructions. All the reactions were performed in five biological replicas in a CFX96 Touch Real-Time PCR Detection System (BioRad). The cycle program used for all cases was $95^{\circ} \mathrm{C}$ for $10 \mathrm{~min}$, and 40 cycles of $95^{\circ} \mathrm{C}$ for $15 \mathrm{sec}$ and $60^{\circ} \mathrm{C}$ for $1 \mathrm{~min}$. 
The genes selected for confirmation by RT-qPCR are shown in Figure 7, and all specially designed primers are listed in Supplemental Table S5.

\section{RNA-seq of microdissected axons and ventral roots}

\section{RNA extraction}

Five axoplasm samples from different animals were pooled before RNA extraction to reach the minimal input amount of linear amplification kit (500 pg). For the ventral root sample, five ventral root samples were pooled and diluted to $500 \mathrm{pg}$ after the first step of RNA extraction (with TRI Reagent, see above). Following that, a second step of RNA extraction (with RNAqueous-Micro Total RNA Isolation Kit) was performed as described above.

\section{RNA linear amplification}

Both microdissected axons and ventral roots pools were subjected to RNA linear amplification using Ovation RNA-Seq System v2 (NuGEN, Tecan), following the manufacturer's recommendations. Quality and quantity of the resulting double-stranded cDNA were evaluated by means of a 2100 Bioanalyzer (Agilent) and Nanodrop 1000 (Thermo Scientific).

\section{Sequencing}

Libraries were constructed and sequenced at BGI Genomics (Hong Kong), on Illumina HiSeq4000 platform.

\section{RNA-seq data processing and analysis}

The raw reads were aligned to the rat reference genome (Rnor_6.0, GCA_000001895.4) using HISAT v2.0.5 (Kim et al. 2015). The mapped reads were assembled by StringTie v1.3.3b (Pertea et al. 2015, 2016) in a reference-based approach ("-e" option). The TPM (transcripts per million reads) method was used to normalize the gene expression in each sample, and lowly expressed ( $<1$ TPM) genes were filtered. The python script "prepDE.py" was used to obtain the count values.

Functional annotation analysis was performed using the Database for Annotation, Visualization, and Integrated Discovery (DAVID) website (v6.8, http://david.abcc.ncifcrf.gov/). The transcripts detected in axoplasm were used as the gene list, and those detected in the ventral root sample were used as background.

For saturation plot and biotypes analysis the NOISeq $\mathrm{R}$ package was used (Tarazona et al. 2015). The graphics were performed using the following $\mathrm{R}$ packages: gplots for heatmap and venneuler (Wilkinson 2012) for proportional Venn diagrams. For Venn diagram of several data sets, a web tool (http:// bioinformatics.psb.ugent.be/webtools/Venn/) was used.

The list of mitochondrial proteins was obtained from MitoMiner database v4.0 (http://mitominer.mrc-mbu.cam.ac.uk/release-4.0/ begin.do (Smith and Robinson 2019), using the Integrated Mitochondrial Protein Index (IMPI).

The PPI networks were performed with the stringApp (Doncheva et al. 2019) of Cytoscape (Shannon et al. 2003).

For comparison of rat with mouse RNA-seq data, the Ensembl BioMart database (Kinsella et al. 2011) was used to scan for ortho- logs between species. Only genes with known orthologs were used in the comparison to avoid inflating the proportion of nonoverlapping genes.

\section{Use of published data sets}

The data used in cross-comparisons of data sets were obtained from the NCBI Gene Expression Omnibus and ArrayExpress Archive. The accession numbers and their respective study references for the axonal transcriptomics studies are as follows: GEO: GSE51572 (Minis et al. 2014), GEO: GSE66230 (Briese et al. 2015), E-MTAB-4978 (Zappulo et al. 2017), and GEO: GSE121069 (Nijssen et al. 2018). The data of RNA-seq was remapped (to the mm10 [mouse] reference genome) and TPM values calculated using the pipeline described above, to avoid differential mapping bias.

\section{Quantification and statistical analysis}

For RT-qPCR and coefficient of variation values, mean and standard deviation is reported. In correlation analysis (Figs. 2C, 6A) the linear regression $r^{2}$ (goodness-of-fit) is reported. In the scatter plot graphics (Fig. 5C; Supplemental Fig. S2B) the mean and 95\% $\mathrm{Cl}$ is presented.

\section{DATA DEPOSITION}

The data sets supporting the results of this article are available at the Sequence Read Archive repository, Project ID: PRJNA598237.

\section{SUPPLEMENTAL MATERIAL}

Supplemental material is available for this article.

\section{ACKNOWLEDGMENTS}

This work was partially supported by Agencia Nacional de Investigación e Innovación (ANII), Programa de Desarrollo de las Ciencias Básicas (PEDECIBA), Science and Innovation Fund from the Foreign and Commonwealth Office-ANII (UK_ID_2015_1_3 to J.R.S.S. and C.E.H.), and Comisión Sectorial de Investigación Científica (CSIC, UdelaR, funding project CSIC Iniciación 2013 \#176 to J.F.). PhD fellowships were awarded to Joaquina Farias (ANII: POS_NAC_2014_1_102151 and Comisión Académica de Posgrados [CAP, UdelaR]). The authors wish to thank Dr. Martin Ciganda for revising the use of English of the manuscript. Special thanks to Professor Edward Koenig, for being a true source of inspiration and support in science and life.

Author contributions: J.R.S. and J.R.S.S. conceived the project; J.R.S.S. developed the methodology and supervised the work; J. F. and J.R.S.S. performed research; J.F. and C.E.H. performed validation using smFISH; J.F. performed data curation; J.F. and J.R. S.S. performed data analysis and interpretation; J.F. and J.R.S.S. drafted the article; J.F., C.E.H., J.R.S., and J.R.S.S. performed critical revisions of the article; J.F., C.E.H., J.R.S., and J.R.S.S. approved the final version to be published. 
Received October 18, 2019; accepted January 31, 2020.

\section{REFERENCES}

Black MM. 2016. Axonal transport: the orderly motion of axonal structures. Methods Cell Biol 131: 1-19. doi:10.1016/bs.mcb.2015.06 .001

Briese M, Saal L, Appenzeller S, Moradi M, Baluapuri A, Sendtner M. 2015. Whole transcriptome profiling reveals the RNA content of motor axons. Nucleic Acids Res 44: 1-19. doi:10.1093/nar/ gkv1027

Brown GC. 2001. Regulation of mitochondrial respiration by nitric oxide inhibition of cytochrome $c$ oxidase. Biochim Biophys Acta 1504: 46-57. doi:10.1016/S0005-2728(00)00238-3

Cagnetta R, Frese CK, Shigeoka T, Krijgsveld J, Holt CE. 2018. Rapid cue-specific remodeling of the nascent axonal proteome. Neuron 99: 29-46.e4. doi:10.1016/j.neuron.2018.06.004

Cajigas IJ, Tushev G, Will TJ, tom Dieck S, Fuerst N, Schuman EM. 2012. The local transcriptome in the synaptic neuropil revealed by deep sequencing and high-resolution imaging. Neuron 74: 453-466. doi:10.1016/j.neuron.2012.02.036

Calliari A, Farías J, Puppo A, Canclini L, Mercer JA, Munroe D, Sotelo JR, Sotelo-Silveira JR. 2014. Myosin Va associates with mRNA in ribonucleoprotein particles present in myelinated peripheral axons and in the central nervous system. Dev Neurobiol 74: 382-396. doi:10.1002/dneu.22155

Capano CP, Giuditta A, Castigli E, Kaplan BB. 1987. Occurrence and sequence complexity of polyadenylated RNA in squid axoplasm. J Neurochem 49: 698-704. doi:10.1111/j.1471-4159.1987 tb00950.x

Cioni JM, Koppers M, Holt CE. 2018. Molecular control of local translation in axon development and maintenance. Curr Opin Neurobiol 51: 86-94. doi:10.1016/j.conb.2018.02.025

Cioni JM, Lin JQ, Holtermann AV, Koppers M, Jakobs MAH, Azizi A, Turner-Bridger B, Shigeoka T, Franze K, Harris WA, et al. 2019. Late endosomes act as mRNA translation platforms and sustain mitochondria in axons. Cell 176: 56-72.e15. doi:10.1016/j.cell.2018 .11 .030

Cornejo V, Luarte A, Couve A. 2017. Global and local mechanisms sustain axonal proteostasis of transmembrane proteins. Traffic 18: 255-266. doi:10.1111/tra.12472

Costa CJ, Willis DE. 2018. To the end of the line: axonal mRNA transport and local translation in health and neurodegenerative disease. Dev Neurobiol 78: 209-220. doi:10.1002/dneu.22555

Doncheva NT, Morris JH, Gorodkin J, Jensen LJ. 2019. Cytoscape StringApp: network analysis and visualization of proteomics data. $J$ Proteome Res 18: 623-632. doi:10.1021/acs.jproteome .8b00702

Donnelly CJ, Willis DE, Xu M, Tep C, Jiang C, Yoo S, Schanen NC, Kirn-Safran CB, Van Minnen J, English A, et al. 2011. Limited availability of ZBP1 restricts axonal mRNA localization and nerve regeneration capacity. EMBO J 30: 4665-4677. doi:10.1038/emboj .2011 .347

Dörrbaum AR, Kochen L, Langer JD, Schuman EM. 2018. Local and global influences on protein turnover in neurons and glia. Elife 7: 1-24. doi:10.7554/eLife.34202

Farias J, Sotelo JR, Sotelo-Silveira J. 2019. Towards axonal system biology: genome wide views of local mRNA translation. Proteomics 19: 1900054. doi:10.1002/pmic.201900054

Fazal FM, Han S, Parker KR, Kaewsapsak P, Xu J, Boettiger AN, Chang HY, Ting AY. 2019. Atlas of subcellular RNA localization revealed by APEX-Seq. Cell 178: 473-490. doi:10.1016/j.cell.2019 .05 .027

Fornasiero EF, Mandad S, Wildhagen $H$, Alevra M, Rammner B, Keihani S, Opazo F, Urban I, Ischebeck T, Sakib MS, et al. 2018.
Precisely measured protein lifetimes in the mouse brain reveal differences across tissues and subcellular fractions. Nat Commun 9: 4230. doi:10.1038/s41467-018-06519-0

Frankel RD, Koenig E. 1978. Identification of locally synthesized proteins in proximal stump axons of the neurotomized hypoglossal nerve. Brain Res 141: 67-76. doi:10.1016/0006-8993(78)90617-0

Fromont-Racine M, Senger B, Saveanu C, Fasiolo F. 2003. Ribosome assembly in eukaryotes. Gene 313: 17-42. doi:10.1016/S03781119(03)00629-2

Gilbert DS. 1975. Axoplasm architecture and physical properties as seen in the Myxicola giant axon. J Physiol 253: 257-301. doi:10 $.1113 /$ jphysiol.1975.sp011190

Glock C, Heumüller M, Schuman EM. 2017. mRNA transport \& local translation in neurons. Curr Opin Neurobiol 45: 169-177. doi:10 $.1016 / j . c o n b .2017 .05 .005$

Griffiths I, Mitchell L, McPhilemy K, Morrison S, Kyriakides E, Barrie J. 1989. Expression of myelin protein genes in Schwann cells. J Neurocytol 18: 345-352. doi:10.1007/BF01190837

Gumy LF, Tan CL, Fawcett JW. 2010. The role of local protein synthesis and degradation in axon regeneration. Exp Neurol 223: 28-37. doi:10.1016/j.expneurol.2009.06.004

Gumy LF, Yeo GSHH, Tung Y-CCL, Zivraj KH, Willis D, Coppola G, Lam BYHH, Twiss JL, Holt CE, Fawcett JW, et al. 2011. Transcriptome analysis of embryonic and adult sensory axons reveals changes in mRNA repertoire localization. RNA 17: 85-98. doi:10.1261/rna.2386111

Hadler-Olsen E, Kanapathippillai P, Berg E, Svineng G, Winberg JO, Uhlin-Hansen L. 2010. Gelatin in situ zymography on fixed, paraffin-embedded tissue: zinc and ethanol fixation preserve enzyme activity. J Histochem Cytochem 58: 29-39. doi:10.1369/jhc.2009 .954354

Hafner AS, Donlin-Asp PG, Leitch B, Herzog E, Schuman EM. 2019. Local protein synthesis is a ubiquitous feature of neuronal preand postsynaptic compartments. Science 364: 650. doi:10.1126/ science.aau3644

Ikenaka K, Katsuno M, Kawai K, Ishigaki S, Tanaka F, Sobue G. 2012. Disruption of axonal transport in motor neuron diseases. Int J Mol Sci 13: 1225-1238. doi:10.3390/ijms13011225

Jadhav A, Wei L, Shi P. 2015. Compartmentalized platforms for neuropharmacological research. Curr Neuropharmacol 14: 72-86. doi:10.2174/1570159X13666150516000957

Jensen UB, Owens DM, Pedersen S, Christensen R. 2010. Zinc fixation preserves flow cytometry scatter and fluorescence parameters and allows simultaneous analysis of DNA content and synthesis, and intracellular and surface epitopes. Cytometry A 77: 798-804. doi:10 .1002/cyto.a.20914

Jirikowski GF, Sanna PP, Bloom FE. 1990. mRNA coding for oxytocin is present in axons of the hypothalamo-neurohypophysial tract. Proc Natl Acad Sci 87: 7400-7404. doi:10.1073/pnas.87.19.7400

Kim D, Langmead B, Salzberg SL. 2015. HISAT: a fast spliced aligner with low memory requirements. Nat Methods 12: 357-360. doi:10 .1038/nmeth.3317

Kinsella RJ, Kahari A, Haider S, Zamora J, Proctor G, Spudich G, Almeida-King J, Staines D, Derwent P, Kerhornou A, et al. 2011. Ensembl BioMarts: a hub for data retrieval across taxonomic space. Database 2011: bar030. doi:10.1093/database/bar030

Koenig E. 1979. Ribosomal RNA in Mauthner axon: implications for a protein synthesizing machinery in the myelinated axon. Brain Res 174: 95-107. doi:10.1016/0006-8993(79)90806-0

Koenig E. 1986. Isolation of native Mauthner cell axoplasm and an analysis of organelle movement in non-aqueous and aqueous media. Brain Res 398: 288-297. doi:10.1016/0006-8993(86) 91488-5

Koenig E. 1991. Evaluation of local synthesis of axonal proteins in the goldfish Mauthner cell axon and axons of dorsal and ventral roots 
of the rat in vitro. Mol Cell Neurosci 2: 384-394. doi:10.1016/ 1044-7431(91)90025-J

Koenig E. 2009. Organized ribosome-containing structural domains in axons. Results Probl Cell Differ 48: 173-191. doi:10.1007/ 400_2008_29

Koenig E, Martin R. 1996. Cortical plaque-like structures identify ribosome-containing domains in the Mauthner cell axon. J Neurosci 16: 1400-1411. doi:10.1523/JNEUROSCI.16-04-01400.1996

Koenig E, Martin R, Titmus M, Sotelo-Silveira JR. 2000. Cryptic peripheral ribosomal domains distributed intermittently along mammalian myelinated axons. J Neurosci 20: 8390-8400. doi:10.1523/ JNEUROSCI.20-22-08390.2000

Kun A, Otero L, Sotelo-Silveira JR, Sotelo JR. 2007. Ribosomal distributions in axons of mammalian myelinated fibers. J Neurosci Res 85: 2087-2098. doi:10.1002/jnr.21340

Leung KM, Van Horck FPG, Lin AC, Allison R, Standart N, Holt CE. 2006. Asymmetrical $\beta$-actin mRNA translation in growth cones mediates attractive turning to netrin-1. Nat Neurosci 9: 1247-1256. doi:10.1038/nn1775

Liao YC, Fernandopulle MS, Wang G, Choi H, Hao L, Drerup CM, Patel R, Qamar S, Nixon-Abell J, Shen Y, et al. 2019. RNA granules hitchhike on lysosomes for long-distance transport, using annexin A11 as a molecular tether. Cell 179: 147-164. doi:10.1016/j.cell .2019 .08 .050

López-Leal R, Alvarez J, Court FA. 2016. Origin of axonal proteins: is the axon-Schwann cell unit a functional syncytium? Cytoskeleton 73: 629-639. doi:10.1002/cm.21319

Luquet E, Biesemann C, Munier A, Herzog E. 2017. Purification of synaptosome populations using fluorescence-activated synaptosome sorting. Methods Mol Biol 1538: 121-134. doi:10.1007/978-14939-6688-2_10

Lykidis D, Van Noorden S, Armstrong A, Spencer-Dene B, Li J, Zhuang Z, Stamp GWH. 2007. Novel zinc-based fixative for high quality DNA, RNA and protein analysis. Nucleic Acids Res 35: e85. doi:10.1093/nar/gkm433

Mathur C, Johnson KR, Tong BA, Miranda P, Srikumar D, Basilio D, Latorre R, Bezanilla F, Holmgren M. 2018. Demonstration of ion channel synthesis by isolated squid giant axon provides functional evidence for localized axonal membrane protein translation. Sci Rep 8: 2207. doi:10.1038/s41598-018-20684-8

Michaelevski I, Medzihradszky KF, Lynn A, Burlingame AL, Fainzilber M. 2010. Axonal transport proteomics reveals mobilization of translation machinery to the lesion site in injured sciatic nerve. Mol Cell Proteomics 9: 976-987. doi:10.1074/mcp .M900369-MCP200

Minis A, Dahary D, Manor O, Leshkowitz D, Pilpel Y, Yaron A. 2014. Subcellular transcriptomics-dissection of the mRNA composition in the axonal compartment of sensory neurons. Dev Neurobiol 74: 365-381. doi:10.1002/dneu.22140

Mohr E, Richter D. 1992. Diversity of mRNAs in the axonal compartment of peptidergic neurons in the rat. Eur J Neurosci 4: 870876. doi:10.1111/j.1460-9568.1992.tb00197.x

Mohr E, Fehr S, Richter D. 1991. Axonal transport of neuropeptide encoding mRNAs within the hypothalamo-hypophyseal tract of rats. EMBO J 10: 2419-2424. doi:10.1002/j.1460-2075.1991 .tb07781.x

Neto E, Leitão L, Sousa DM, Alves CJ, Alencastre IS, Aguiar P, Lamghari M. 2016. Compartmentalized microfluidic platforms: the unrivaled breakthrough of in vitro tools for neurobiological research. J Neurosci 36: 11573-11584. doi:10.1523/JNEUROSCI .1748-16.2016

Nijssen J, Benitez JA, Hoogstraaten R, Kee N, Hedlund E. 2018. Axonseq decodes the motor axon transcriptome and its modulation in response to ALS. Stem Cell Rep 11: 321596. doi:10.1016/j.stemcr .2018 .11 .005
Ouwenga R, Lake AM, O'Brien D, Mogha A, Dani A, Dougherty JD. 2017. Transcriptomic analysis of ribosome-bound mRNA in cortical neurites in vivo. J Neurosci 37: 3044-3016. doi:10.1523/ JNEUROSCI.3044-16.2017

Peña C, Hurt E, Panse VG. 2017. Eukaryotic ribosome assembly, transport and quality control. Nat Struct Mol Biol 24: 689-699. doi:10 1038/nsmb.3454

Pertea M, Pertea GM, Antonescu CM, Chang TC, Mendell JT, Salzberg SL. 2015. StringTie enables improved reconstruction of a transcriptome from RNA-seq reads. Nat Biotechnol 33: 290295. doi:10.1038/nbt.3122

Pertea M, Kim D, Pertea GM, Leek JT, Salzberg SL. 2016. Transcriptlevel expression analysis of RNA-seq experiments with HISAT, StringTie and Ballgown. Nat Protoc 11: 1650-1667. doi:10 .1038/nprot.2016.095

Quijano C, Trujillo M, Castro L, Trostchansky A. 2016. Interplay between oxidant species and energy metabolism. Redox Biol 8: 28-42. doi:10.1016/j.redox.2015.11.010

Rishal I, Michaelevski I, Rozenbaum M, Shinder V, Medzihradszky KF, Burlingame AL, Fainzilber M. 2010. Axoplasm isolation from peripheral nerve. Dev Neurobiol 70: 126-133. doi:10.1002/dneu .20755

Rotem N, Magen I, lonescu A, Gershoni-Emek N, Altman T, Costa CJ, Gradus T, Pasmanik-Chor M, Willis DE, Ben-Dov IZ, et al. 2017. ALS along the axons-expression of coding and noncoding RNA differs in axons of ALS models. Sci Rep 7: 44500. doi:10.1038/ srep44500

Roy S. 2014. Seeing the unseen: the hidden world of slow axonal transport. Neuroscientist 20: 71-81. doi:10.1177/ 1073858413498306

Saal L, Briese M, Kneitz S, Glinka M, Sendtner M. 2014. Subcellular transcriptome alterations in a cell culture model of spinal muscular atrophy point to widespread defects in axonal growth and presynaptic differentiation. RNA 20: 1789-1802. doi:10.1261/rna .047373 .114

Shannon P, Markiel A, Ozier O, Baliga N, Wang J, Ramage D, Ami N, Schwikowski B, Ideker T. 2003. Cytoscape: a software environment for integrated models of biomolecular interaction networks. Genome Res 13: 6. doi:10.1101/gr.1239303

Shi Z, Fujii K, Kovary KM, Genuth NR, Röst HL, Teruel MN, Barna M. 2017. Heterogeneous ribosomes preferentially translate distinct subpools of mRNAs genome-wide. Mol Cell 67: 71-83. doi:10 .1016/j.molcel.2017.05.021

Shigeoka T, Jung $H$, Jung J, Turner-Bridger B, Ohk J, Lin JQ, Amieux PS, Holt CE. 2016. Dynamic axonal translation in developing and mature visual circuits. Cell 166: 181-192. doi:10.1016/j cell.2016.05.029

Shigeoka T, Koppers M, Wong HHW, Lin JQ, Cagnetta R, Dwivedy A, de Freitas Nascimento J, van Tartwijk FW, Ströhl F, Cioni JM, et al. 2019. On-site ribosome remodeling by locally synthesized ribosomal proteins in axons. Cell Rep 29: 3605-3619. doi:10.1016/j .celrep.2019.11.025

Skutella T, Probst JC, Blanco E, Jirikowski GF. 1994. Localization of tyrosine hydroxylase mRNA in the axons of the hypothalamo-neurohypophysial system. Mol Brain Res 23: 179-184. doi:10.1016/ 0169-328X(94)90224-0

Smith AC, Robinson AJ. 2019. Mitominer v4.0: an updated database of mitochondrial localization evidence, phenotypes and diseases. Nucleic Acids Res 47: D1225-D1228. doi:10.1093/nar/gky1072

Snipes G, Suter U, Welcher A, Shooter E. 1992. Characterization of a novel peripheral nervous system myelin protein (PMP- 22/SR13). J Cell Biol 117: 225-238. doi:10.1083/jcb.117.1.225

Sotelo JR, Canclini L, Kun A, Sotelo-Silveira JR, Calliari A, Cal K, Bresque M, Dipaolo A, Farias J, Mercer JA. 2014. Glia to axon RNA transfer. Dev Neurobio/ 74:292-302. doi:10.1002/dneu.22125 
Sotelo-Silveira JR, Calliari A, Kun A, Benech JC, Sanguinetti C, Chalar C, Sotelo JR. 2000. Neurofilament mRNAs are present and translated in the normal and severed sciatic nerve. J Neurosci Res 62: 65-74. doi:10.1002/1097-4547(20001001)62:1<65::AID-JNR7>3 .0.CO;2-Z

Sotelo-Silveira JR, Calliari A, Cárdenas M, Koenig E, Sotelo JR. 2004. Myosin Va and kinesin II motor proteins are concentrated in ribosomal domains (periaxoplasmic ribosomal plaques) of myelinated axons. J Neurobiol 60: 187-196. doi:10.1002/neu .20015

Sotelo-Silveira J, Crispino M, Puppo A, Sotelo JR, Koenig E. 2008. Myelinated axons contain $\beta$-actin mRNA and ZBP- 1 in periaxoplasmic ribosomal plaques and depend on cyclic AMP and F-actin integrity for in vitro translation. $J$ Neurochem 104: 545-557.

Szklarczyk D, Franceschini A, Wyder S, Forslund K, Heller D, HuertaCepas J, Simonovic M, Roth A, Santos A, Tsafou KP, et al. 2015. STRING v10: protein-protein interaction networks, integrated over the tree of life. Nucleic Acids Res 43: D447-D452. doi:10 .1093/nar/gku1003

Tarazona S, Furió-Tarí P, Turrà D, Di Pietro A, Nueda MJ, Ferrer A, Conesa A. 2015. Data quality aware analysis of differential expression in RNA-seq with NOISeq R/Bioc package. Nucleic Acids Res 43: e140. doi:10.1093/nar/gkv711

Taylor AM, Berchtold NC, Perreau VM, Tu CH, Li Jeon N, Cotman CW. 2009. Axonal mRNA in uninjured and regenerating cortical mammalian axons. J Neurosci 29: 4697-4707. doi:10.1523/ JNEUROSCI.6130-08.2009

Thakurela S, Garding A, Jung RB, Müller C, Goebbels S, White R, Werner HB, Tiwari VK. 2016. The transcriptome of mouse central nervous system myelin. Sci Rep 6: 25828. doi:10.1038/ srep25828

Tóth EN, Lohith A, Mondal M, Guo J, Fukamizu A, Pourmand N. 2018. Single-cell nanobiopsy reveals compartmentalization of mRNAs within neuronal cells. J Biol Chem 293: 4940-4951. doi:10 .1074/jbc.M117.800763

Wang B, Bao L. 2017. Axonal microRNAs: localization, function and regulatory mechanism during axon development. J Mol Cell Biol 9: 82-90. doi:10.1093/jmcb/mjw050
Warner JR, Mclntosh KB. 2009. How common are extraribosomal functions of ribosomal proteins? Mol Cell 34: 3-11. doi:10.1016/ j.molcel.2009.03.006

White R, Gonsior C, Krämer-Albers E-M, Stöhr N, Hüttelmaier S, Trotter J. 2008. Activation of oligodendroglial Fyn kinase enhances translation of mRNAs transported in hnRNP A2-dependent RNA granules. J Cell Biol 181: 579-586. doi:10.1083/jcb.200706164

Wilkinson L. 2012. Exact and approximate area-proportional circular Venn and Euler diagrams. IEEE Trans Vis Comput Graph 18: 321-331. doi:10.1109/TVCG.2011.56

Willis DE, Van Niekerk EA, Sasaki Y, Mesngon M, Merianda TT, Williams GG, Kendall M, Smith DS, Bassell GJ, Twiss JL. 2007. Extracellular stimuli specifically regulate localized levels of individual neuronal mRNAs. J Cell Biol 178: 965-980. doi:10.1083/jcb 200703209

Willis DE, Xu M, Donnelly CJ, Tep C, Kendall M, Erenstheyn M, English AW, Schanen NC, Kirn-Safran CB, Yoon SOO, et al. 2011. Axonal localization of transgene mRNA in mature PNS and CNS neurons. J Neurosci 31: 14481-14487. doi:10.1523/ JNEUROSCI.2950-11.2011

Wong HHW, Lin JQ, Ströhl F, Roque CG, Cioni JM, Cagnetta R, Turner-Bridger B, Laine RF, Harris WA, Kaminski CF, et al. 2017. RNA docking and local translation regulate site-specific axon remodeling in vivo. Neuron 95: 852-868. doi:10.1016/j.neuron .2017.07.016

Yao J, Sasaki Y, Wen Z, Bassell GJ, Zheng JQ. 2006. An essential role for $\beta$-actin mRNA localization and translation in $\mathrm{Ca}^{2+}$-dependent growth cone guidance. Nat Neurosci 9: 1265-1273. doi:10 .1038/nn1773

Zappulo A, Van Den Bruck D, Ciolli Mattioli C, Franke V, Imami K, McShane E, Moreno-Estelles M, Calviello L, Filipchyk A, Peguero-Sanchez E, et al. 2017. RNA localization is a key determinant of neurite-enriched proteome. Nat Commun 8: 583. doi:10 .1038/s41467-017-00690-6

Zivraj KH, Tung YCL, Piper M, Gumy L, Fawcett JW, Yeo GSHH, Holt CE. 2010. Subcellular profiling reveals distinct and developmentally regulated repertoire of growth cone mRNAs. J Neurosci 30: 15464-15478. doi:10.1523/JNEUROSCI.1800-10 .2010 

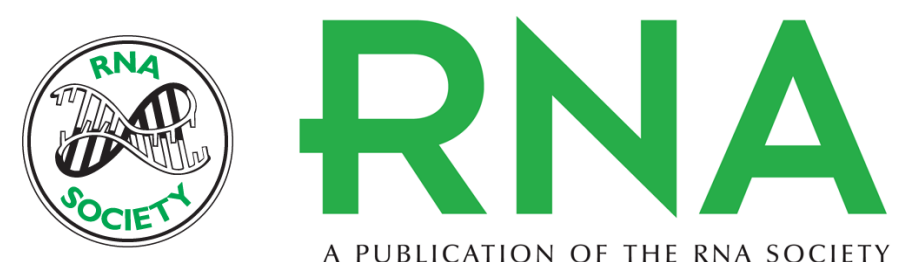

A PUBLICATION OF THE RNA SOCIETY

\title{
Axon microdissection and transcriptome profiling reveals the in vivo RNA content of fully differentiated myelinated motor axons
}

\author{
Joaquina Farias, Christine E. Holt, José R. Sotelo, et al.
}

RNA 2020 26: 595-612 originally published online February 12, 2020

Access the most recent version at doi:10.1261/rna.073700.119

\section{Supplemental http://rnajournal.cshlp.org/content/suppl/2020/02/12/rna.073700.119.DC1 \\ Material}

References This article cites 86 articles, 14 of which can be accessed free at: http://rnajournal.cshlp.org/content/26/5/595.full.html\#ref-list-1

Creative This article is distributed exclusively by the RNA Society for the first 12 months after the Commons full-issue publication date (see http://rnajournal.cshlp.org/site/misc/terms.xhtml). After 12

License months, it is available under a Creative Commons License (Attribution-NonCommercial 4.0 International), as described at http://creativecommons.org/licenses/by-nc/4.0/.

Email Alerting
Service

Receive free email alerts when new articles cite this article - sign up in the box at the top right corner of the article or click here.

To subscribe to $R N A$ go to:

http://rnajournal.cshlp.org/subscriptions 